Article

\title{
Analysis of Non-Symmetrical Heat Removal During Cast- ing of Steel Billets and Slabs
}

\author{
Adán Ramírez-López ${ }^{1}$, Omar Dávila-Maldonado ${ }^{2}$, Alfonso Nájera-Bastida ${ }^{3}$, Rodolfo D. Morales ${ }^{2,}$, Jafeth \\ Rodríguez-Ávila ${ }^{4}$ and Carlos Rodrigo Muñiz-Valdés ${ }^{4}$
}

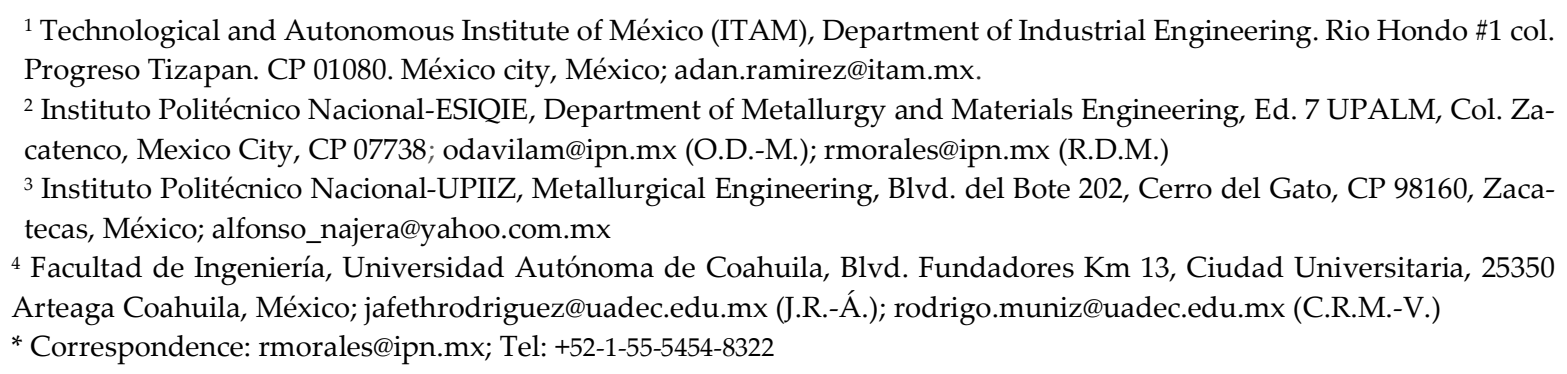

Abstract: The Current automation of steelmaking processes is capable of complete control through programmed hardware. However, many metallurgical and operating factors, such as heat transfer control, require further studies under industrial conditions. On this line, computer simulation has become a powerful tool for reproducing the effects of industrial constraints on heat transfer. This work reports a computational model to simulate heat removal from billets strands in the continuous casting process. This model deals with the nonsymmetric cooling conditions of a billet caster. These cooling conditions frequently happen due to plugged nozzles in the secondary cooling system (SCS). The model developed simulates the steel thermal behavior for casters with a non-symmetric distribution of the sprays in the SCS using different boundary conditions to show possible heat transfer variations. Finally, the results are compared with actual temperatures from different casters to demonstrate the predictive capacity of this algorithm's approach.

Keywords: Heat removal; Finite difference method; Computer simulation; Continuous casting.

\section{Introduction}

Steel is one of the essential materials in the world's civilization. It is essential to produce many products such as pipelines, mechanical elements in machines, vehicles, profiles, and beam sections for buildings in many industries. Until the ' 50 s of the $20^{\text {th }}$ century, steel products required a complex process known as ingot casting; for years, steelmakers focused on developing and simplifying this process. The result was the continuous casting process (CCP); it is the most productive method to produce steel. The CCP allows producing significant volumes of steel sections without interruption and is more productive than the formal ingot casting process. The CCP begins by transferring the liquid steel from the steel-ladle to a tundish. This tundish or vessel distributes the liquid steel, by flowing through its volume, to one or more strands having water-cooled copper molds. The mold is the primary cooling system, PCS, solidifying a steel shell to withstand a liquid core and its friction forces with the mold wall.

Further down the mold, the rolls drive the steel section in the SCS. Here the steel section is cooled, solidifying the remaining liquid core, by sprays placed in every cooling segment all around the billet and along the curved section of the machine. Finally, the steel strand goes towards a horizontal-straight free-spray zone, losing heat by radiation mechanism, where the billet cools down further to total solidification. A moving torch cuttingscissor splits the billet to the desired length at the end of this heat-radiant zone.

During the $\mathrm{CCP}$, the steel composition, the geometrical configuration of the continuous casting machine (CCM), and the operating conditions directly affect the billet heat removal and its solidification profiles along 
the machine's length. To conduct the process under certain operating circumstances, appropriate casting conditions and heat extracting parameters reduce the risks of accidents such as breakouts and other undesirable situations that may affect the production and the quality of steel products. Many authors reported simulation results of heat removal conditions during CCP [1-22]. Some of them began using elementary mathematical models using semi-empirical equations to approach heat removal. The computational capacities were limited in the '60s, '70s, and ' 80 s $[2,13,20]$ to deal with the heat transfer problem. The use of numerical methods was not immediately adopted to solve complex problems [12,14-18]. Today, the improvements in data speed processing and the increment in-memory storage allow the software to solve complex problems quickly with complicated calculation routines using substantial data arrays. Moreover, programming methods and techniques provide the user with more efficient tools, algorithms, and friendlier computer environments.

During the CCP of the steel, heat transfer simulation involves calculating the heat removal divided into the three stages (PCS, SCS, and the radiation zone) [1,3-5,7,8,11-19]. Many authors used equations with different coefficients obtained from actual temperature measurements due to the complexity of heat removal in the mold. Savage and Pritchard are the beginners who took measurements from casting molds to predict the heat flux through the mold wall [20]. In the same way, others used interpolation methods to obtain equations representing heat removal conditions in the SCS [1,3-5,7-8]. These equations are general models for the entire SCS. However, some of them developed equations for each segment of the SCS to obtain more accurate results. In this work, the calculation of the heat removal capacity through spray-cooling employs the physical properties of the cooling water [11-19,22-24]. The heat flux in the radiation zone requires a simple calculation as the only Equation required is that for radiation. Finally, the model calculates the heat flux inside the steel section, solving the heat conduction equation again to agree with the internal heat re-distribution [25-27,30].

The temperature profile shown in Figure 1 results after applying uniform heat removal conditions to the four billet surfaces. Here the isothermal zones are symmetrical in each direction. The geometry of the solidification front goes from quasi-squared-linear faces to the billet corners and surfaces to a circle in the billet core [26,28-31]. Nevertheless, this profile is related to an ideal heat removal which is the most straightforward simplified assumption for the heat removal problem. However, there is the need for different heat removal conditions on each billet surface due to the fluctuation of the water flow rate and water temperature [6,11,26-29] acting on each surface. Other needs of cooling control is toe decrease segregation levels [32], using appropriate heat transfer coefficients [33], using dynamic spray cooling and temperature monitoring [34-37]. Besides, many operational problems arise during casting operations, such as a non-homogeneous supply of the water on the billet surface, boiling heat transfer mechanism of water close to the cold mold face, and bent or plugging spray nozzles. Thus, defining features and boundary conditions permit special heat removal conditions [38-42].

\section{Computational Representation of Steel Casting.}

Initially, a definition of steel using mathematical terms in the model is necessary. The computation procedure involves the discretization of volume elements of a squared steel section using finite difference techniques, the designation of dimensions of this volume is $1 x, 1 y$, and $1 z$. The inclusion of each 3D element is an independent node in a squared mesh stored in a $2 \mathrm{D}$ computational array. The calculation of the element sizes $(\Delta \mathrm{x})$ and $(\Delta \mathrm{y})$ are functions of the billet section and the elements used for discretization. The calculation of the magnitude of the dimension in the cast direction $(\Delta \mathrm{z})$ obeys the stability criterion calculated according to the casting speed. The user defines the number of nodes $(\mathrm{Nx})$ and $(\mathrm{Ny})$. The identification of the array is by the literals in the subindexes $(\mathrm{I})$ and $(\mathrm{J})$. The solution of the heat transfer equation is through a finite difference method employing nested loops [23-24,38-42]. The thermo-physical properties, such as thermal conductivity $(\mathrm{k})$ and heat capacity $\left(C_{p}\right)$ for steel, are functions of temperature and chemical composition [14-18,22-24]. 


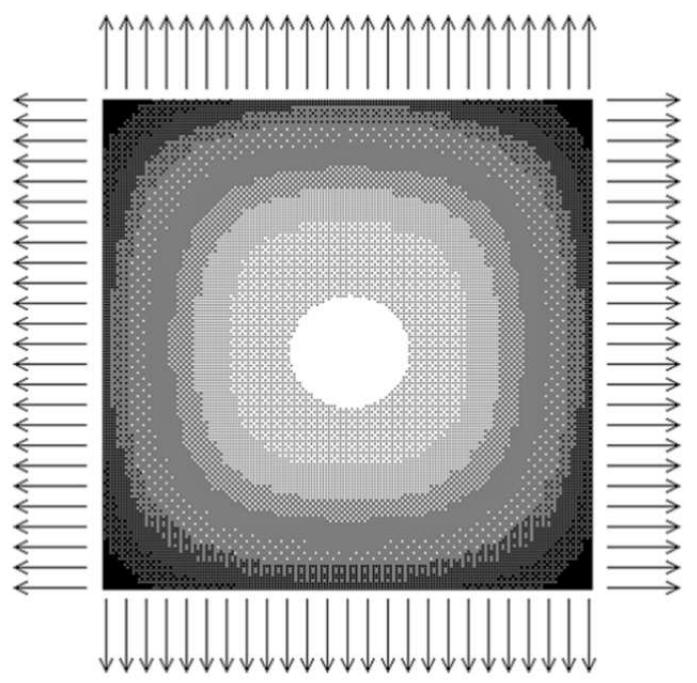

Figure 1. A typical temperature profile in the cross section of a steel billet.

The following assumptions constitute part of the models applied in this work:

- The casting temperature (TCO) is the same for all the nodes. Thus, the assignment of the energy required to define the casting temperature is for all nodes.

- Only one single steel volume is in the casting plant for the simulation. In consequence, there is no heat inter-change in the longitudinal direction of the machine. Thus, the heat removal in the cast direction is negligible. This assumption simplifies the problem and reduces the calculation time; the problem is a 2D type as the longitudinal heat transfer is negligible. Therefore, the treatment of the problem uses 2D computational arrays, one for enthalpies and one more for the latest and previous calculations of enthalpy $\left(\mathrm{H}_{\mathrm{I}}, \mathrm{J}^{\mathrm{t}-1}\right.$ and $\left.\mathrm{T}_{\mathrm{I}} \mathrm{J}^{\mathrm{t}-1}\right)$ and $\left(\mathrm{H}_{\mathrm{I}}, \mathrm{Jt}\right.$ and $\left.\mathrm{T}_{\mathrm{I}}, \mathrm{Jt}\right)$, reducing the computer's memory requirements.

- The simulation begins at the meniscus level inside the mold. Then the simulation time is $(\mathrm{t}=0)$.

- The step time $(\Delta \mathrm{t})$ is calculated as a function of the billet dimensions (lx) and (ly), using (Nx) and (Ny) nodes, and the steel thermal diffusivity $(\alpha)$, is given in Equations (1) and (2).

$$
\alpha=\frac{k}{\rho C_{p}}
$$

The counting of Iterations includes the entire algorithm-loop to calculate the heat transfer and the corresponding routines for displaying and saving the information nested inside. Every iteration corresponds to the results obtained after updating the actual simulation time with the step time $(t=t+\Delta t)$. The step time $(\Delta t)$ obeys the criterion given by Equation (2), and its estimation is through the casting speed by knowing the dimension $(\Delta \mathrm{z})$ of the steel volume control.

$$
\Delta t=\frac{\Delta x \Delta y}{4 \alpha}
$$

The calculation of transformation temperatures for steel ( $\mathrm{T}_{\mathrm{Liq}}, \mathrm{T}_{\mathrm{Sol}}, \mathrm{T}_{\mathrm{AR} 1}, \& \mathrm{~T}_{\mathrm{AR} 3}$ ) is through Equations (3)(6) as a function of the steel chemical composition [22]. Therefore, Equation (7) calculates the corresponding energy required to melt the steel $\left(\mathrm{H}_{\mathrm{I}, \mathrm{J}}\right)[3,15,22]$. Here $(\mathrm{w})$ is the weight of each discretized steel element, obtained using Equation (8). A graphical representation of the energy calculated for a steel volume is in Figure 2. 


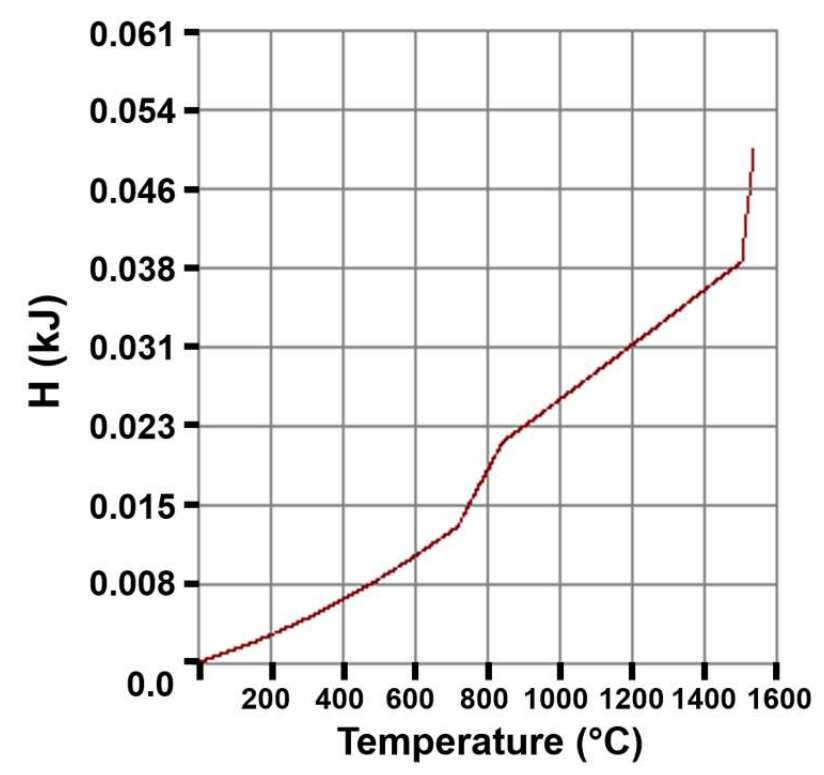

Figure 2. Relationship between enthalpy and temperature for a steel billet.

$$
\begin{aligned}
& T_{L i q}=1537-88 \% C-25 \% S-5 \% C u-8 \% S i-5 \% M n-2 \% M o-4 \% N i-1.5 \% C r- \\
& 18 \% T i-2 \% V-30 \% P \\
& T_{\text {Sol }}=1535-200 \% \mathrm{C}-12.3 \% \mathrm{Si}-6.8 \% \mathrm{Mn}-124.5 \% \mathrm{P}-183.9 \% \mathrm{~S}-4.3 \% \mathrm{Ni}- \\
& 1.4 \% \mathrm{Cr}-4.1 \% \mathrm{Al} \\
& T_{A R}=723-10.7 \% M n-16.9 \% N i+21.9 \% S i+16.9 \% C r+290 \% A s+6.38 \% W \\
& T_{A R 3}=910-203 \% C-15.2 \% N i+44.7 \% S i+104 \% V+31.5 \% M o+13.1 \% W-(30 \% M n+ \\
& 11 \% \mathrm{Cr}+20 \% \mathrm{Cu}-700 \% \mathrm{P}-400 \% \mathrm{Al}-120 \% \mathrm{As}-400 \% \mathrm{Ti}) \\
& H=q=\int_{T=T_{0}}^{T=T_{A R 1}} W c_{p} d T+\int_{T=T_{A R 1}}^{T=T_{A R}} W c_{p} d T+\int_{T=T_{A R 3}}^{T=T_{S o l}} W c_{p} d T+\int_{T=T_{S o l}}^{T=T_{L i q}} W c_{p} d T+\int_{T=T_{L i q}}^{T=T_{\infty}} W c_{p} d T \\
& w=\Delta x \cdot \Delta y \cdot \Delta z \cdot \rho_{\text {steel }}
\end{aligned}
$$

Some authors simulated the billet thermal behavior during CCP considering only $1 / 4$ or $1 / 2$ of the cast section and assuming symmetric heat removal as is described in Figure 3 [1-4,10,13-17]. Heat removal takes place only through the lateral surfaces, and there is a heat conduction assumption on the rest of the sample. Formerly, the application of this procedure was due to limited computer capacities at the time. Now, more promising approaches are possible, better programming models to simulate accurately more complex and no symmetrical operating conditions. 


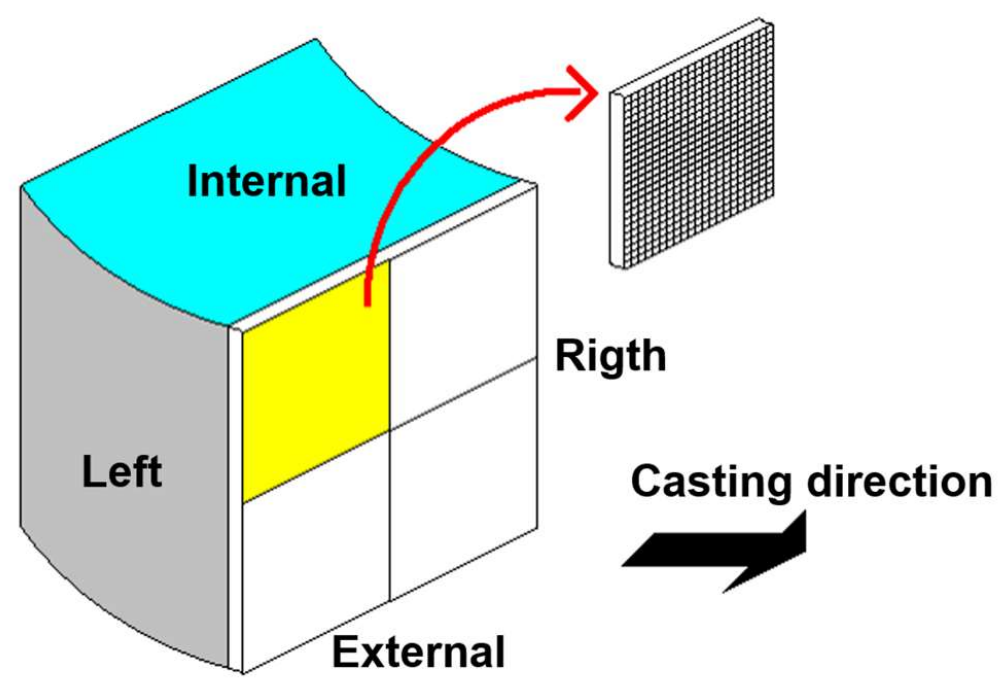

Figure 3. Billet faces used in the mold. Internal and external faces refer to the internal and external radius of the machine radius of curvture. The het flow is symmetric.

\section{Heat Removal and Conduction Inside the Billet Core.}

The first step during the calculation process is to obtain the temperatures in the external nodes at each step time $(t+\Delta t)$. The new value of enthalpy in the external nodes is feasible by using Equation (9). The enthalpy value for every node $\left(\mathrm{H}_{\left.\mathrm{I}, \mathrm{t}^{t}\right)}\right)$ is the last, and the heat removal is $\left(\mathrm{q}_{\mathrm{I}, \mathrm{J}}\right)$. Then the new values are stored in a new array for the next iteration, and the previous array is deleted and updated for efficient use of the computational resources. The calculation of the applied heat removal to every node in the billet surfaces (q,J) is a function of the mechanism involved according to the billet position and the CCM [5-7,24-26].

$$
H_{I, J}^{t}=H_{I, J}^{t-1}-q_{I, J}
$$

Similarly as presented in equation (7); for each value of enthalpy $\left(\mathrm{H}_{\mathrm{I}, \mathrm{J}}\right)$ correspond a value of temperature $\left(\mathrm{T}_{\mathrm{I}, \mathrm{J}}\right)[13,15,26-29]$. The main routine updates the heat that remained after each step time $(\Delta \mathrm{t})$ during the simulation. If the cast speed is known; it is possible to calculate exactly the time when each node changes from liquid to a mushy structure and from a mushy structure to solid-state, as is indicated in Equation (10), and then storing

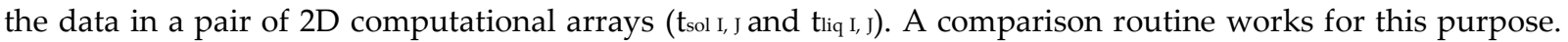
This routine is applied to all external and internal nodes and is included in the main calculation routine to update the information. Here the superscripts $(t)$ and $(t-1)$ represent the corresponding values of the latest and the previous iterations during the simulation time. Computationally these values correspond to the actual time $(\mathrm{t})$ and the previous simulated time $(\mathrm{t}-\Delta \mathrm{t})$.

$$
H_{I, J}^{t} \rightarrow T_{I, J}^{t} \rightarrow t_{\text {sol } I, J^{\prime}}, t_{l i q_{I, J}}, t_{\text {mush } I, J}
$$

The best fit for calculating the mold's heat removal is possible by using equations that involve dwelling time, as Savage and Pritchard demonstrated [20]. In the present work, the algorithms use Equation (11) to calculate heat removal using the coefficients calculated by these authors, but the sub-indexes (s) provide the user the option to define different heat removal conditions to each billet surface. Heat removal is considered a complex problem, and many authors prefer to treat it using coefficients as a function of dwell time.

$$
q_{s}=A_{o_{s}}+B_{o_{s}} \sqrt{t}
$$

Heat removal in the SCS is due to 2 mechanisms. When steel is under a sprayed zone, the heat removal is intense, and the surface temperature decreases due to the forced convection. Nevertheless, when the steel is running under a no-sprayed area, the heat removal is through the radiation mechanism, and the billet surface temperature increases due to the latent heat flux coming out from the core [6,9,21-24]. Equations (12) and (13) calculate the heat removal under sprayed and no sprayed areas, respectively. Here the heat flux (q) is a function of a heat transfer coefficient (h), which results from the previous calculation of the water flow applied in the 
nozzles. This calculation includes the evaluation of the Prandtl, Nusselt, and Reynolds numbers. In the boundary $\left(T_{\mathrm{w}}\right)$ and $\left(\mathrm{T}_{\mathrm{L}, \mathrm{J}}\right)$ are the water and billet surface temperatures. Equation (13) is the Stefan-Boltzmann's and calculates the heat flux value as a function of the steel emissivity $(\varepsilon)$. These two heat removal conditions work during the simulation when the geometrical conditions of the CCM are verified and validated. The result is a temperature curve that goes down when steel is under a sprayed area and goes up when steel is under a nosprayed area. The entire process to calculate the coefficient " $\mathrm{h}$ " solves the equations (14-17). The sub-indexes "ns" and "side" indicate that these values can differ for every segment of the SCS and every billet side. The subindex " $w$ " identifies the liquid used as water. $(\varepsilon)$ is the emissivity, $(\mu)$ is the dynamic water viscosity, the subindexes (I) and (J) identify the nodal positions of the billet surface.

$$
\begin{gathered}
q_{s}=h_{f}\left(T_{I, J}-T_{w}\right) \\
q_{s}=\sigma \varepsilon\left(T_{I, J}^{4}-T_{a m b}^{4}\right) \\
R e_{n s, \text { side }}=\frac{d_{w n s, s i d e} v_{w n s ; s i d e} \rho_{w n s, \text { side }}}{\mu} \\
P r_{n s, \text { side }}=\frac{c_{p} \mu}{k} \\
N u_{n s, \text { side }}=c \operatorname{Re}^{n} \operatorname{Pr}^{0.333} \\
h_{n s, \text { side }}=\frac{N u_{n s, \text { side }} k}{D}
\end{gathered}
$$

Within the billet core, conduction is the only heat transfer mechanism involved. The heat re-distribution is available by solving the partial differential Equation (18), which explains that a temperature profile exists for the steel volume at each time step of the simulation $(t+\Delta t)$. The enthalpy and temperature calculations include the billet's frontal billet face at each step time. The solution of this Equation includes a pair of nested loops to calculate each node temperature of the steel volume. Using the information of the nearest neighbors in the previous iteration and solving the mathematical Equation (19) through the Crank-Nicholson Method [6,9,10] makes feasible the determination of the temperature field.

$$
\begin{gathered}
\left(\frac{\partial^{2} T}{\partial x^{2}}+\frac{\partial^{2} T}{\partial y^{2}}\right)=\frac{1}{\alpha} \frac{\partial T}{\partial t} \\
\frac{1}{(\Delta x)^{2}}\left(T_{I-1, J}+T_{I+1, J}-2 T_{I, J}\right)+\frac{1}{(\Delta y)^{2}}\left(T_{I, J-1}+T_{I, J+1}-2 T_{I, J}\right)=\frac{1}{\alpha_{I, J}} \frac{T_{I, J}^{t+1}-T_{I, J}^{t}}{\Delta t}
\end{gathered}
$$

In the computing flowchart shown in Figure 4, the need to separate the external and internal nodes of the analyzed mesh is evident there. The calculation of the external nodes proceeds in agreement with the steel position and the CCM for each time step $(t+\Delta t)$. 


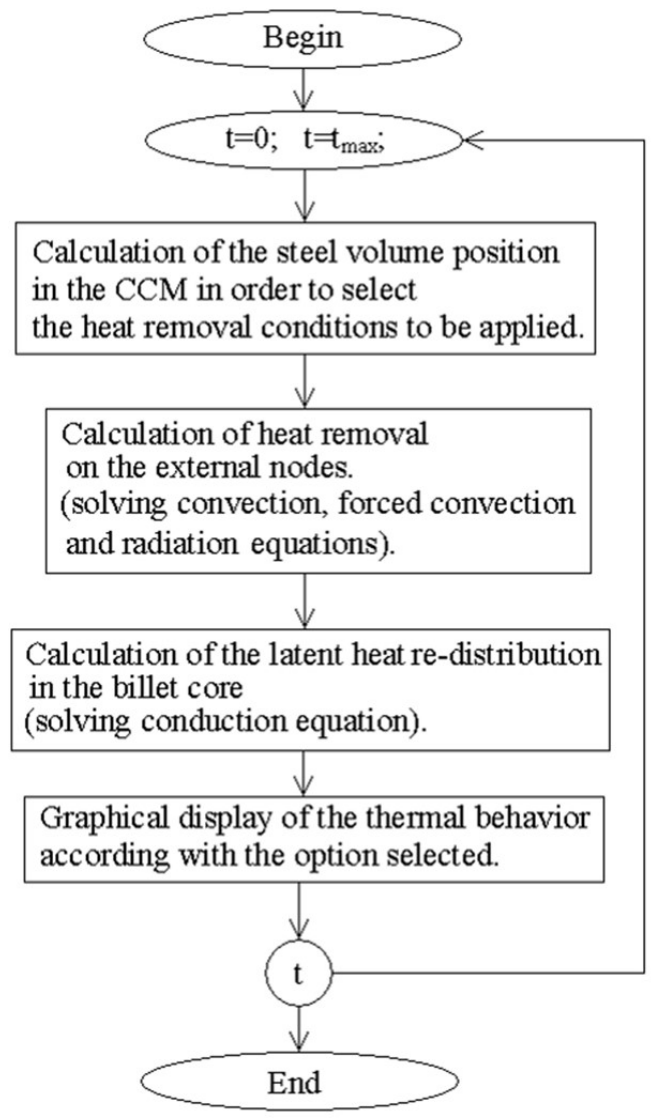

Figure 4. Flow chart of the mathematical model.

Storing the information about heat removal during simulation in two-dimensional computational arrays woks to feed the information in the solution process in the mold. The data stored for defining the operating conditions have three locations referred to the coefficients of the Savage and Pritchard equation, which defines the final heat flux removal [20]; then, for PCS, the array used is:

$$
\text { PCS }=[\text { Surface }],[\text { coefficient 1], [coefficient 2] }
$$

For the SCS, a five-dimensional computational array defines all the operating conditions in the SCS. The locations have the following format:

$$
\text { SCS }=[\text { Segment }],[\text { Spray }],[\text { Surface }],[\text { Lateral Position }],[\text { Data }]
$$

The first box refers to the cooling segment having different spray distributions. Then the second box defines the position in the SCS of the control volume at any time. By comparing with the running distance is possible to know exactly under what spray is the billet element. Then the appropriated heat removal is applied according to the corresponded surface. More lateral sprays can be defined if necessary. The data file storages all the information required for each spray, such as (water flow rate, temperature, and shooting angle). Segments and sprays are ordered numerically for easy recognition using integers to store the corresponding values. A numerical code identifies the billet surface where the heat removal is applied. The code employed is: (1) is used for external radius side of the billet, (2) for internal radius side of the billet, (3) for left, and (4) for the right billet surfaces, respectively. The only restriction is that all these values must be larger than zero.

Figures $5 \mathbf{a}-5 \mathrm{~h}$ show different industrial spray arrangements for an SCS applied to billet continuous casting machines. Here four sprays around the billet surfaces are placed at the same arrangement and apply the same water flow rate. 


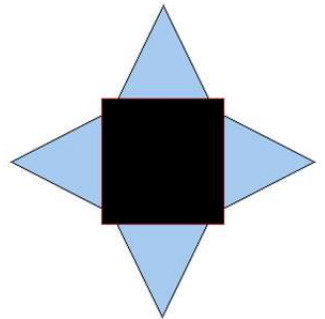

(a)

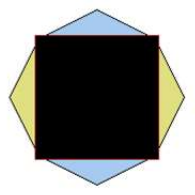

(e)

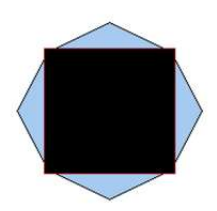

(b)

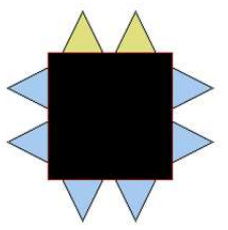

(f)

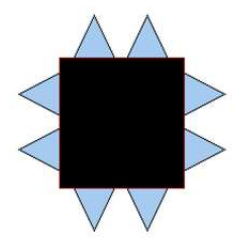

(c)

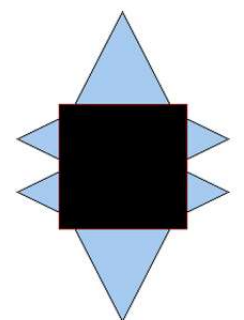

(g)

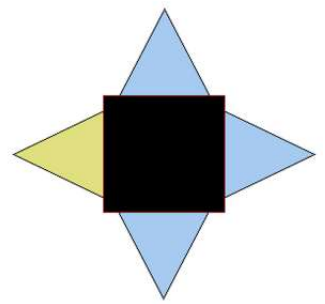

(d)

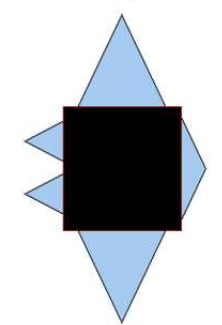

(h)

Figure 5. (a-h) Different arrangements of billet cooling sprays in continuous casting machines.

Then, the same heat flux works in the four billet surfaces resulting in symmetrical temperature profiles. Figure $5 \mathrm{~b}$ shows a version of the original shooting angle $[8,10,16,22-24]$, and Figure $5 \mathrm{c}$ shows another symmetrical spray arrangement, but more than one spray shooting water over the billet surfaces. These figures provide a homogeneous heat removal. Figures $5 \mathrm{~d}$ to $5 \mathrm{f}$ show the same spray configuration but with different water flow rates over one or two billet surfaces, yielding different heat fluxes. Figures $5 \mathrm{~g}$ and $5 \mathrm{~h}$ show that different spray arrangements for heat removal performing differently for each billet surface. There are different spray configurations during the casting of slabs, especially for quenching internal and external faces, which are the broad faces, as is shown in Figure 6.

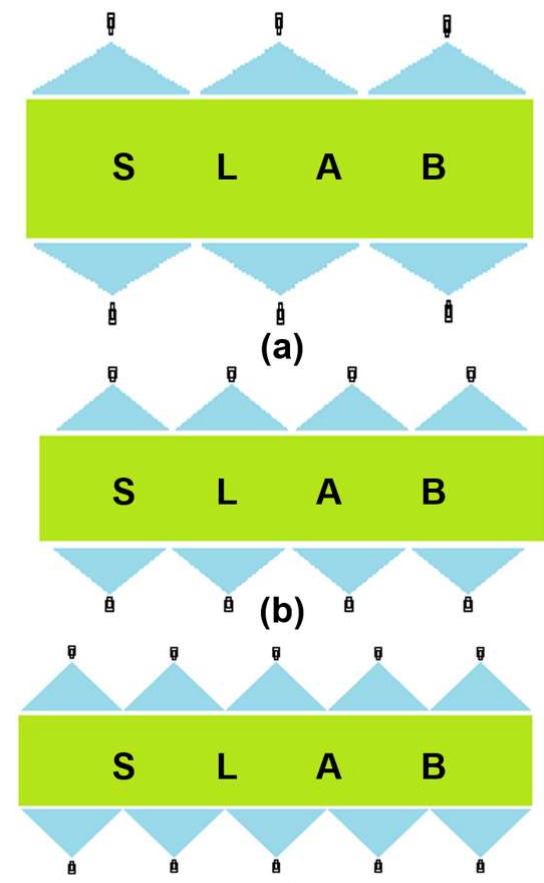

(c)

Figure 6. (a-c) Different arrangements of slab cooling sprays in continuous casting machines. 


\section{Process Simulation.}

\section{Case 1}

The information about the CCM geometry used as input data for the simulation corresponds to a current caster, including the billet section dimensions, shown in Table 1. The casting temperature and the phase changing temperatures were calculated according to the steel composition shown in Tables 2 and 3 . The iterating conditions for each segment of the SCS are in Table 4. Here the number of sprays is the same in segments (1) and (2) but not in segment (3) as is shown in the CCM layout of Figure 7; moreover, the operating conditions such as the water flow rate and the shooting angle $(\Omega)$ are also different for each segment. Consequently, there are no symmetrical heat removal conditions quenching the steel billet surface.

Table 1. Casting conditions.

\begin{tabular}{cccccc}
\hline $\begin{array}{c}\text { Cast Speed } \\
(\mathbf{m} / \mathbf{m i n})\end{array}$ & Casting Temperature $\left({ }^{\circ} \mathbf{C}\right)$ & $\boldsymbol{R}_{\boldsymbol{C}}$ & $\boldsymbol{\theta}_{\mathbf{0}}$ & $\boldsymbol{l}_{\boldsymbol{x}}$ & $\boldsymbol{l}_{\boldsymbol{y}}$ \\
\hline 2.40 & & $(\mathbf{m})$ & & & \\
\hline
\end{tabular}

Table 2. Temperatures of the steel.

\begin{tabular}{cccc}
\hline $\boldsymbol{T}_{\text {ariq }}$ & $\boldsymbol{T}_{\text {sol }}$ & $\boldsymbol{T}_{\boldsymbol{A R 3}}$ & $\boldsymbol{T}_{\boldsymbol{A R} \mathbf{1}}$ \\
$\left({ }^{\circ} \mathrm{C}\right)$ & $\left({ }^{\circ} \mathrm{C}\right)$ & $\left({ }^{\circ} \mathrm{C}\right)$ & $\left({ }^{\circ} \mathrm{C}\right)$ \\
\hline 1524.38 & 1507.85 & 844.07 & 721.04 \\
\hline
\end{tabular}

Table 3. Steel composition in mass \%.

\begin{tabular}{ccccccc}
\hline $\mathbf{C}$ & $\mathbf{A l}$ & $\mathbf{C r}$ & $\mathbf{C u}$ & $\mathbf{M n}$ & $\mathbf{N b}$ & $\mathbf{M o}$ \\
\hline 0.380 & 0.003 & 0.05 & 0.040 & 1.050 & 0.002 & 0.002 \\
\hline $\mathbf{N i}$ & $\mathbf{P}$ & $\mathbf{T i}$ & $\mathbf{S}$ & $\mathbf{S i}$ & $\mathbf{S n}$ & $\mathbf{V}$ \\
\hline 0.006 & 0.014 & 0.002 & 0.018 & 0.200 & 0.001 & 0.002 \\
\hline
\end{tabular}

Table 4. Operating conditions of the SCS (segments 1, 2 and 3).

\begin{tabular}{|c|c|c|c|c|c|c|c|c|c|c|c|c|}
\hline \multirow{2}{*}{$\begin{array}{l}\text { Segment } \\
\text { Surface }\end{array}$} & \multicolumn{4}{|c|}{1} & \multicolumn{4}{|c|}{2} & \multicolumn{4}{|c|}{3} \\
\hline & Int. & Ext. & Left & Right & Int. & Ext. & Left & Right & Int. & Ext. & Left & Right \\
\hline $\begin{array}{l}\text { Water flow rate } \\
\qquad(1 / \mathrm{min})\end{array}$ & 7 & 10 & 7 & 10 & 7 & 10 & 7 & 10 & 7 & 10 & 7 & 10 \\
\hline $\begin{array}{l}\text { Sprays on cast } \\
\text { direction }\end{array}$ & 3 & 3 & 3 & 3 & 6 & 6 & 6 & 6 & 13 & 12 & 9 & 9 \\
\hline $\begin{array}{l}\text { Sprays on the } \\
\text { lateral direction }\end{array}$ & 2 & 2 & 2 & 2 & 1 & 1 & 1 & 1 & 1 & 1 & 1 & 1 \\
\hline
\end{tabular}




\begin{tabular}{cccc}
\hline $\begin{array}{c}\text { Nozzle diameter } \\
(\mathbf{m})\end{array}$ & 0.003 & 0.003 & 0.003 \\
\hline $\boldsymbol{\Omega}_{\text {cast dir }}$ & 50 & 60 & 60 \\
\hline $\boldsymbol{\Omega}_{\text {lateral dir }}$ & 60 & 50 & 50 \\
\hline $\boldsymbol{D}_{\boldsymbol{b s}}(\mathrm{m})$ & 0.083 & 0.100 & 0.100 \\
\hline $\boldsymbol{\theta}$ & 3 & 17 & 25 \\
\hline
\end{tabular}

Operating conditions and assumptions.

The information about the CCM geometry used as input data for the simulation corresponds to a current caster, including the billet section dimensions, shown in Table 1 . The casting temperature and the phase changing temperatures were calculated according to the steel composition shown in Tables 2 and 3. The iterating conditions for each segment of the SCS are in Table 4. Here the number of sprays is the same in segments (1) and (2) but not in segment (3) as is shown in the CCM layout of Figure 7; moreover, the operating conditions such as the water flow rate and the shooting angle $(\Omega)$ are also different for each segment. Consequently, there are no symmetrical heat removal conditions quenching the steel billet surface.

The simulation takes into count the following further assumptions:

- The steel composition is homogeneous.

- The cast speed is constant during the simulation.

- The heat removal inside the mold is constant and equal on each side of the billet.

- The operating and quenching conditions are constants during the casting operation.

The model developed calculates different solidification rates with intense or weak heat removal to include all probable risks. Moreover, a water supply failure simulation is also possible by defining some segments or sprays with a low-value water flow rate equal to zero if it is absent.

The CCM in Figure 7 and casting conditions described in Tables 1 to 4 belong to case (1) for analysis and validation purposes, as found in the following lines. Here (RC) is the curved radius of the CCM, $(\theta)$ is the angle of every segment measured as a function of $(\mathrm{RC})$, and $\left(\theta_{0}\right)$ is the first angle of the SCS and, measured from the end of the mold. $(\Omega)$ is the shooting angle of every spray.

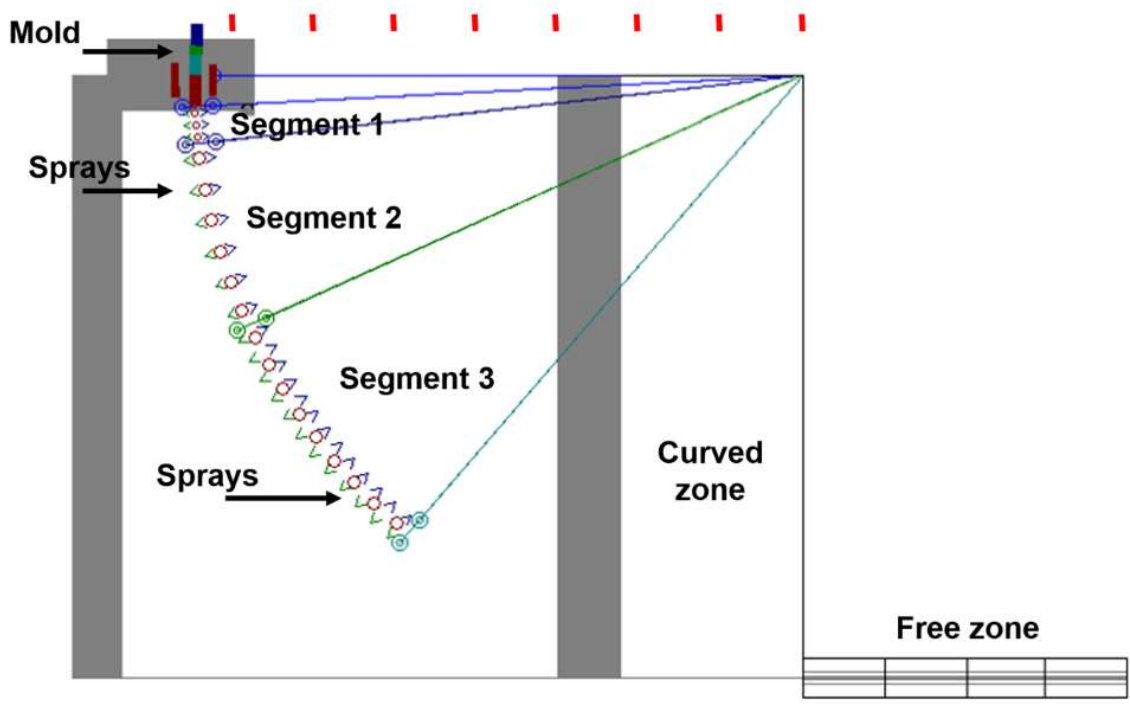

Figure 7. Layout of the billet casting machine corresponding to case 1. 


\section{Simulations and results.}

Figure 8a shows the corresponding surface temperature to each billet surface [23,24]. The simulation includes the curved region of the CCM to appreciate details of the no symmetrical temperature profiles. The close-up of Figure $8 \mathrm{~b}$ illustrates the influence of different spray disposals along the casting direction.

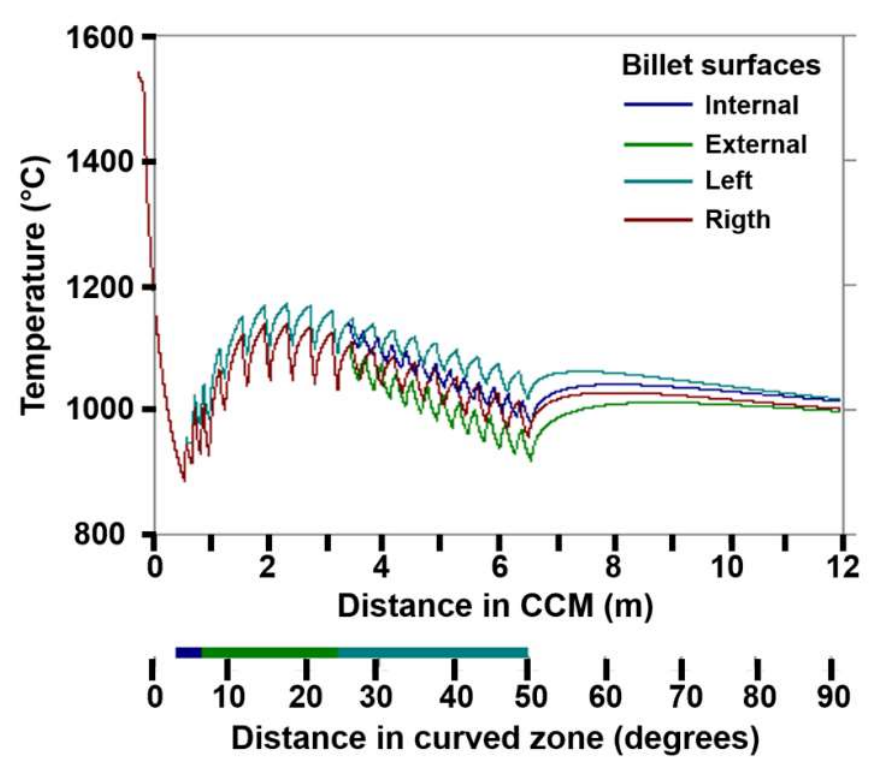

(a)

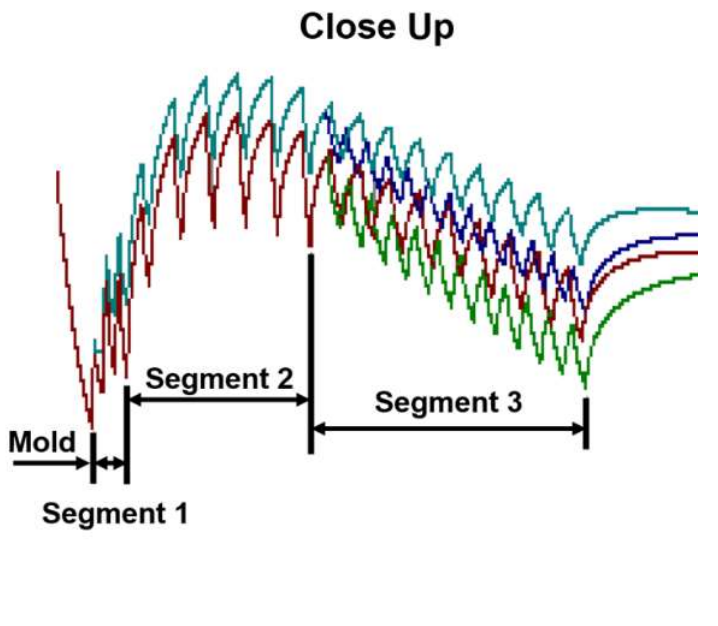

(b)

Figure 8. (a-b) Temperature on the billet surfaces due to symmetrical heat removal applied (consequence of a no symmetrical spray distribution and different water flow rates).

The temperature on billet surfaces becomes different in the segments of the SCS because of the different heat removal conditions applied. There is the same number of sprays in the first and second segments in the lateral and casting directions, but the water flow rates are different. Consequently, different curves diverge at the end of the mold position for these segments, as shown in Figure 8. The other two curves for the corresponding billet surfaces are behind these because the sprays are at the same distance and with the same heat removal conditions. This condition also evidences the precision of the algorithm, the method, and the effectiveness of the number of the nodes employed. The difference between the other curves is not significant, and the curves are hidden or superimposed. The 40,000 nodes used for simulation generated no significant errors after every step time due to blunders and rounded methods without a strong influence on the temperature profiles.

During the first two segments, the curve with the highest temperatures is because of the lowest flow rates (left billet surface), and the lowest temperatures are due to the highest water flow rates (right billet surface). Moreover, Figure 8 shows a temperature difference due to the different spray arrangements along the cast direction in segment 3 of the SCS. There are 13 and 12 sprays for quenching the internal and external sides, but there are only nine sprays along the left and right billet side surfaces. Moreover, the curves for internal and external billet surface temperatures arise as continuity lines from left and right curves, respectively.

In the third segment, the water flow rates and the number of sprays along the cast direction are different. Then four curves are displayed in this segment due to the different sprays and water flow rates used to quench each billet surface. Figures $9 \mathrm{a}$ to $9 \mathrm{c}$ show the corresponding temperature profiles in the mold. These figures are symmetrical due to the same heat removal conditions applied to the four billet surfaces. The corresponding temperature profiles to the SCS are in Figures 10a to 10i. Here the symmetry of the profiles inside the mold is slowly missed. In Figures 10a and 10b, the circles in the core billet are deformed, and the isothermal regions near corners are different and no symmetrical. In Figures $10 \mathrm{~h}$ and 10i, the circular isotherms are deformed and 
moved toward the surfaces with the highest removal heat; furthermore, the isotherms adopt a hyperbolic shape evidencing the non-symmetrical heat removal pattern, including the liquid core.

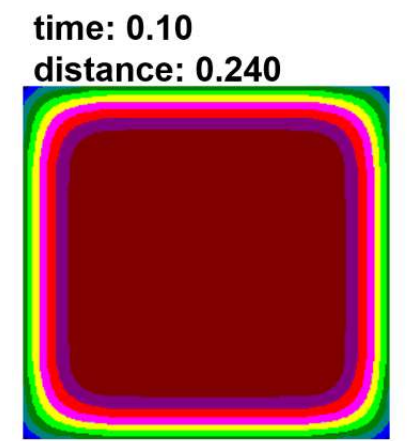

(a)

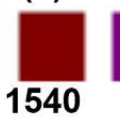

time: $\mathbf{0 . 2 0}$

distance: $\mathbf{0 . 4 8 0}$

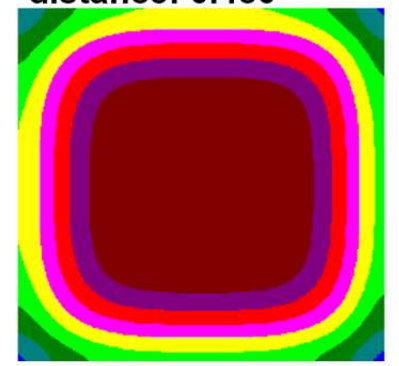

(b) time: $\mathbf{0 . 3 0}$

distance: $\mathbf{0 . 7 2 0}$

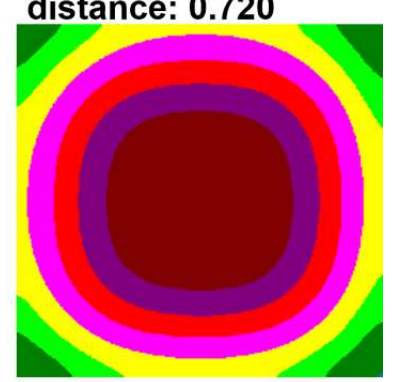

(c)

Figure 9. (a-c) Temperature profiles inside the mold (assumed symmetrical removal). The positions of these profiles are a function of the distance taking as a reference the meniscus level; time ( $\mathrm{min}$ ) and distance $(\mathrm{m})$

Finally, at the end of the SCS, the temperatures of the four surfaces tend to homogenize due to the heat removal by radiation out the SCS which is less intense, and the heat conducted redistributes inside the billet core. Figures 11a to $11 \mathrm{f}$ show the temperature profiles in the free or radiation region of the CCM. Here the latent heat inside the billet core is slowly distributed, tending to adopt a homogeneous temperature. Figure 8 shows the thermal conditions of the surface at the end when the billet is driven out of the CCM, see Figure 8 .

The influence over temperature profiles is more evident near the billet surfaces than in the billet center because of heat removal conditions applied. The corners are the coldest places because the (perimeter/area) ratio is larger than in the middle of the billet surfaces. In other words, for the same area, there is a more extended perimeter where the heat flux works. These influences are in all Figures 8-11. Although considerable changes in the steel thermal behavior are evident in Figures 9 to 11, sometimes the influence over the solidification profile is not significant due to the small temperature difference between ( $\mathrm{T}_{\mathrm{Liq}}$ ) and (Tsol), depending on the steel chemistry.

\section{Case 2}

Figure 12 shows another example for a different layout of a CCM, the configuration and the operating conditions are in Table 5. Figure 13 shows the temperature profiles and the curves of surface temperatures. The simulated billet is a square with section of $(0.125 \times 0.125 \mathrm{~m})$; the cast speed is $2.40 \mathrm{~m} / \mathrm{min}$, and the curved radius of the CCM is $7.95 \mathrm{~m}$. The same mesh (200x200 nodes) is helpful for the calculation. 


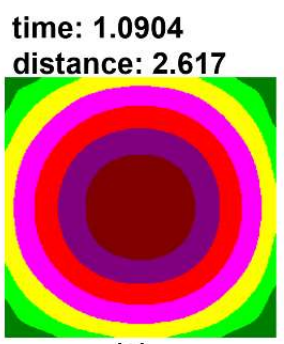

(a)

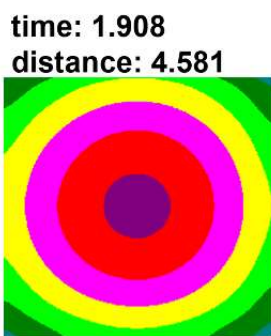

(d)

time: $\mathbf{2 . 7 2 6}$

distance: 6.544

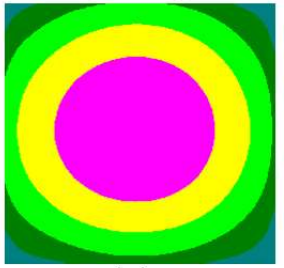

(g) time: 1.363

distance: $\mathbf{3 . 2 7 2}$

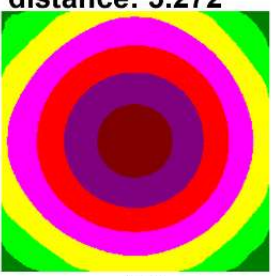

(b)

time: 2.181

distance: $\mathbf{5 . 2 3 5}$

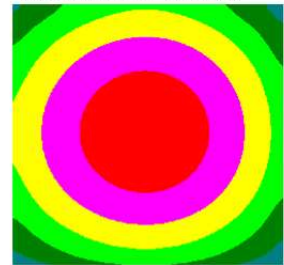

(e)

time: 2.999

distance: 7.199

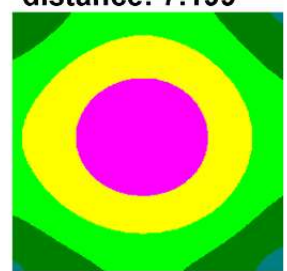

(h) time: 1.635

distance: 3.926

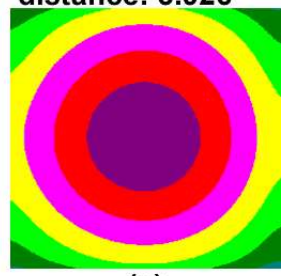

(c)

time: 2.454

distance: $\mathbf{5 . 8 9 0}$

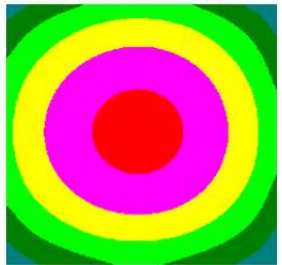

(f)

time: $\mathbf{3 . 2 7 2}$

distance: 7.530

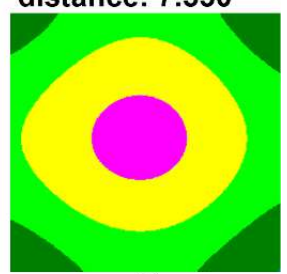

(i)

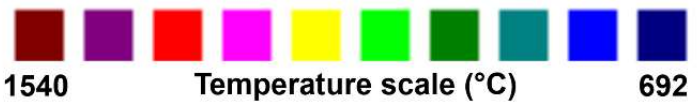

Figure 10. (a-i) Temperature profiles in the SCS. Here the temperatures profiles becomes in no symmetrical due to different water flows rates are applied to quench every side; time ( $\mathrm{min}$ ) and distance $(\mathrm{m})$.

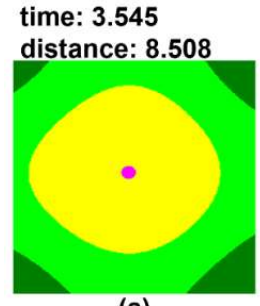

(a)

time: 4.363

distance: 10.472

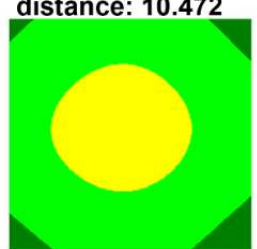

(d)

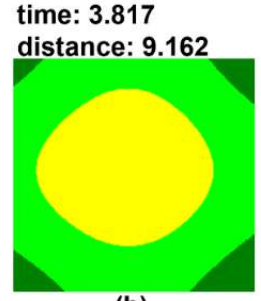

(b)

time: 4.636

distance: 11.126

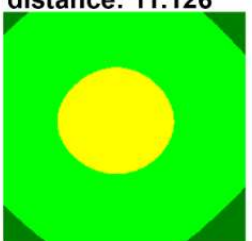

(e)

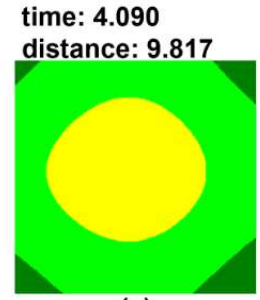

(c)

time: $\mathbf{4 . 8 7 5}$

distance: 11.780

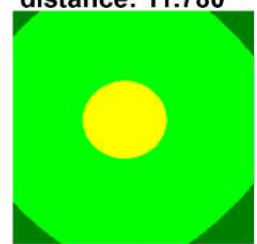

(f)

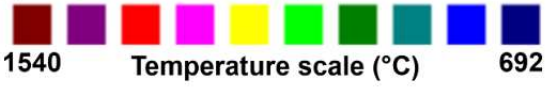

Figure 11. (a-f) Temperature profiles in the free zone; time (min) and distance (m). 
Table 5. Operation conditions of the SCS (segments 1, 2 and 3), Case 2.

\begin{tabular}{|c|c|c|c|c|c|c|c|c|c|c|c|c|}
\hline \multirow{2}{*}{$\begin{array}{l}\text { Segment } \\
\text { Surface }\end{array}$} & \multicolumn{4}{|c|}{1} & \multicolumn{4}{|c|}{2} & \multicolumn{4}{|c|}{3} \\
\hline & $\begin{array}{l}\text { Inter } \\
\text { nal }\end{array}$ & $\begin{array}{l}\text { Exter } \\
\text { nal }\end{array}$ & Left & Right & $\begin{array}{l}\text { Inter } \\
\text { nal }\end{array}$ & $\begin{array}{c}\text { Exter } \\
\text { nal }\end{array}$ & Left & Right & $\begin{array}{l}\text { Inter } \\
\text { nal }\end{array}$ & $\begin{array}{c}\text { Exter } \\
\text { nal }\end{array}$ & Left & Right \\
\hline $\begin{array}{l}\text { Water flow rate } \\
\qquad(1 / \mathrm{min})\end{array}$ & 15 & 15 & 25 & 22 & 12 & 12 & 17 & 15 & 9 & 9 & 12 & 10 \\
\hline $\begin{array}{l}\text { Sprays on cast } \\
\text { direction }\end{array}$ & \multicolumn{4}{|c|}{8} & \multicolumn{4}{|c|}{11} & \multicolumn{4}{|c|}{8} \\
\hline $\begin{array}{l}\text { Sprays on the } \\
\text { lateral direction }\end{array}$ & 1 & 1 & 1 & 1 & 1 & 1 & 1 & 1 & 1 & 1 & 1 & 1 \\
\hline $\begin{array}{l}\text { Nozzle diameter } \\
\qquad(\mathrm{m})\end{array}$ & \multicolumn{12}{|c|}{0.003} \\
\hline $\boldsymbol{\theta}$ & \multicolumn{4}{|c|}{7.50} & \multicolumn{4}{|c|}{22.5} & \multicolumn{4}{|c|}{30} \\
\hline $\mathbf{\Omega}$ & \multicolumn{4}{|c|}{80} & \multicolumn{4}{|c|}{60} & \multicolumn{4}{|c|}{60} \\
\hline$D_{b s}(\mathrm{~m})$ & \multicolumn{4}{|c|}{0.060} & \multicolumn{4}{|c|}{0.110} & \multicolumn{4}{|c|}{0.075} \\
\hline
\end{tabular}

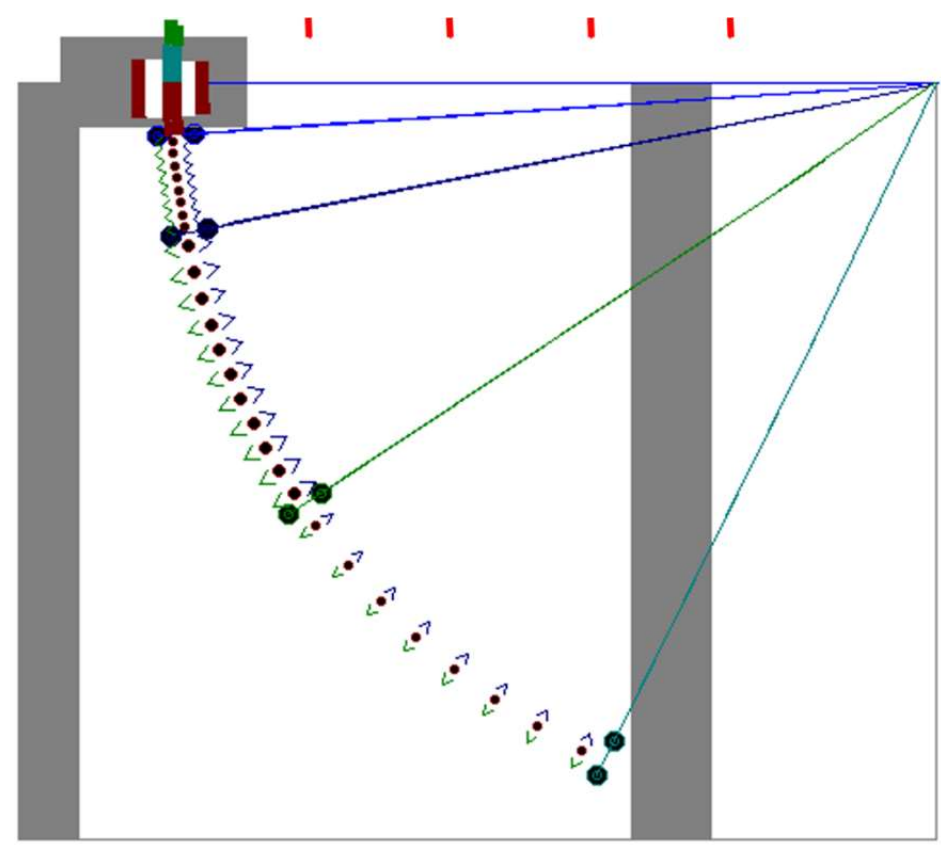

Figure 12. Layout of a symmetrical CCM (curved zone), case 2.

Here only one single line represents the temperature when the steel remains inside the mold. Then three different curves diverge when the billet is in the first segment due to the sprayed areas along the cast direction. When the billet is in the second and third segments, an alternate quenching and reheating behavior appears due to different heat removal rates. The coldest zones due to corner effects are also affected, showing no homogeneous behavior. Finally, at the end of the curved zone where no more spray segments quench the billet surfaces, all the temperatures tend to adopt the same behavior due to heat flowing from the core. 
Although the CCM is symmetrical different surface temperatures resulted after the analysis due to different applied heat fluxes to each billet face. Figure $\mathbf{1 4}$ shows a set of perpendicular views. Here, it is possible to observe that only one single curve is inside the mold due to applying the same heat removal on the four billet surfaces, as shown in Figures 14a and 14b.The non-symmetric profiles emerge when the billet is in the SCS from Figures $14 \mathrm{c}$ to $14 \mathrm{r}$. The isothermal regions changed to rotated squared profiles because of the uneven heat removal rates applied at short distances on the billet surfaces. Moreover, some profiles tend to adopt the same hyperbolic form inside the billet core, like those shown in case (1).

\section{Case 3}

Figure 15 shows a layout of a CCM used for casting steel slabs. It is more significant than a billet caster, and there are more segments in the SCS because a bigger steel volume needs a longer quenching process. Furthermore, cast speeds are also slower than those for casting billets due to the same reason. The general casting conditions are in Table 6, the CCM geometry and operating conditions are in Tables 7 and 8, respectively. Table 7 is divided into two sections to identify the values for the curved and straight zones. Here (ds) is the distance from the nozzle to the slab surface; this is a known data, (dw) and (dnw) are calculated and so are the sprayed and no-sprayed distances. The sub-index (zn) is the identification of a segment.

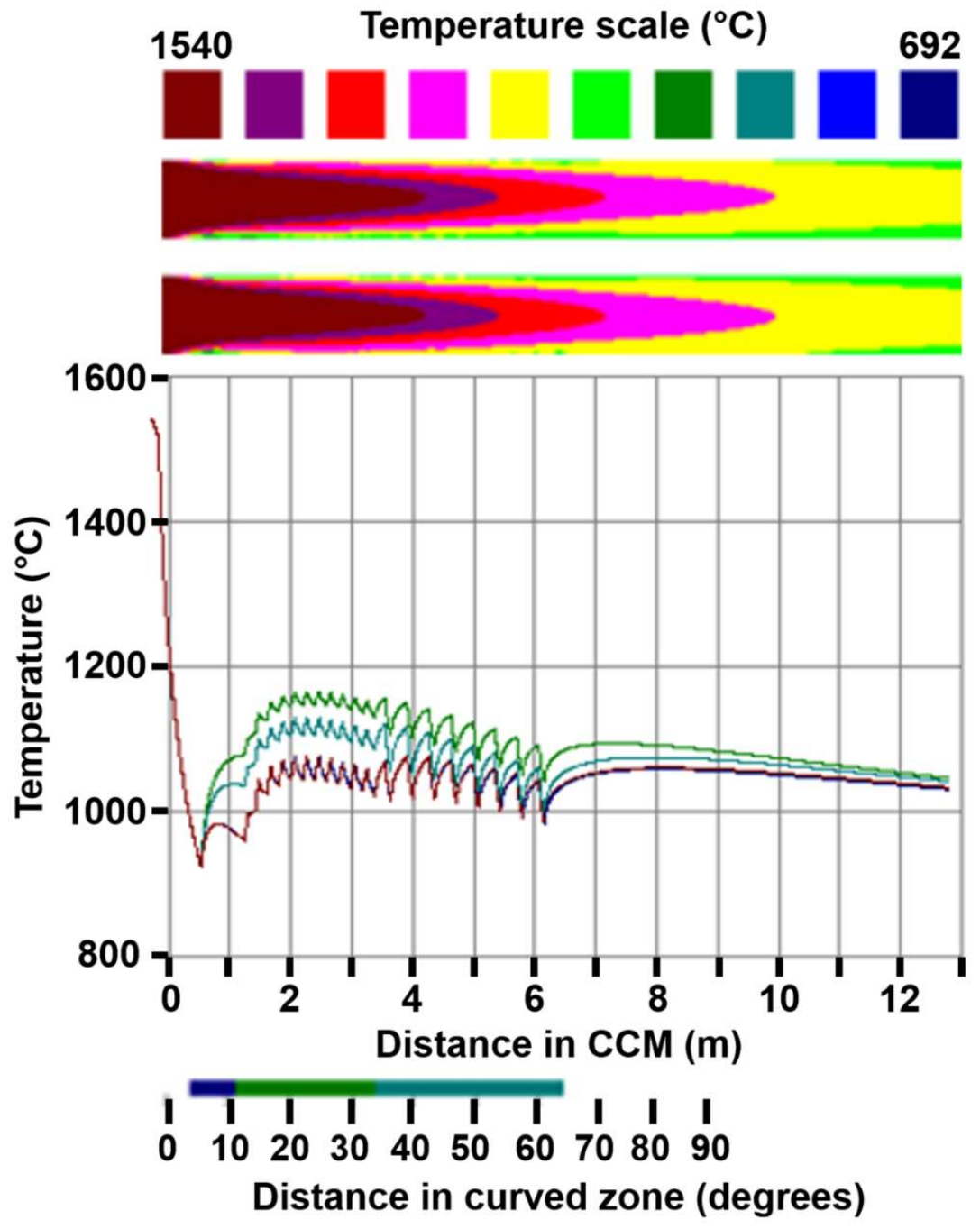

Figure 13. Temperature profiles and surface temperature of a squared billet with no homogeneous heat removal 
Table 6. General configuration of the CCM for casting slabs.

\begin{tabular}{|c|c|c|c|c|c|c|}
\hline $\begin{array}{c}\text { Cast } \\
\text { temperature } \\
\left({ }^{\circ} \mathrm{C}\right)\end{array}$ & $\begin{array}{l}R_{C} \\
(\mathrm{~m})\end{array}$ & $\theta_{0}$ & $\begin{array}{l}\text { Narrow side } \\
\qquad \begin{array}{c}\left(D_{x}\right) \\
(\mathrm{mm})\end{array}\end{array}$ & $\begin{array}{c}\text { Broad side } \\
\qquad\left(D_{y}\right) \\
(\mathrm{mm})\end{array}$ & $\begin{array}{l}\text { Mold length } \\
\text { (m) }\end{array}$ & $\begin{array}{c}\text { Meniscus } \\
\text { level } \\
(\%)\end{array}$ \\
\hline 1545 & 10.5 & 23.5 & 200 & 1100 & 1.10 & 82 \\
\hline
\end{tabular}

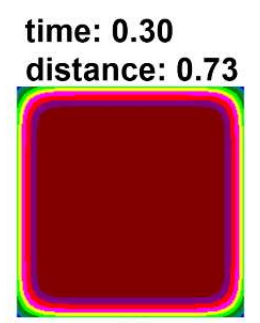

(a)

time: $\mathbf{2 . 1 2}$

distance: 5.08

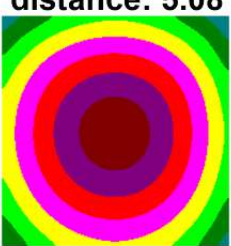

(g)

time: 3.93

distance: 9.43

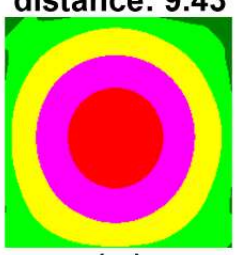

(m)

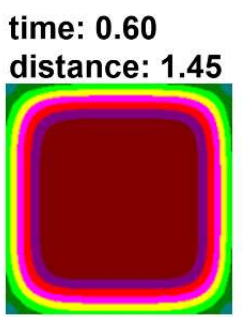

(b)

time: 2.42

distance: $\mathbf{5 . 8 0}$

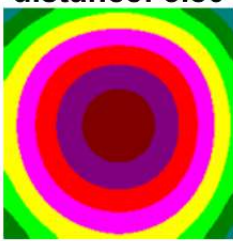

(h)

time: $\mathbf{4 . 2 3}$

distance: 10.15

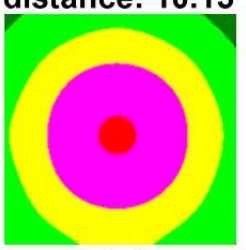

(n)

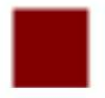

1540

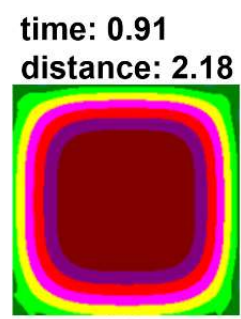

(c)

time: 2.72

distance: 6.53

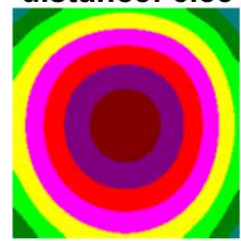

(i)

time: 4.54

distance: 10.88

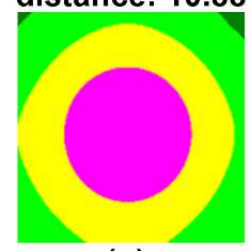

(o)

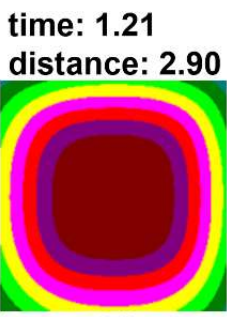

(d)

time: $\mathbf{3 . 0 2}$

distance: 7.25

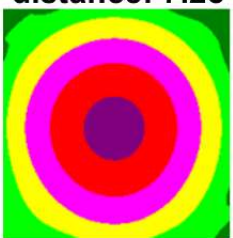

(j)

time: 4.84

distance: 11.60

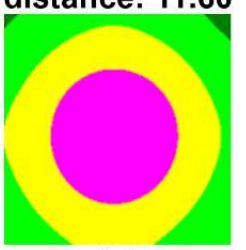

(p)
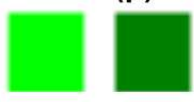

Temperature scale $\left({ }^{\circ} \mathrm{C}\right)$

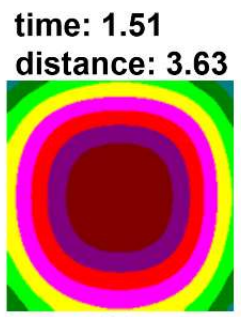

(e)

time: $\mathbf{3 . 3 3}$

distance: 7.98

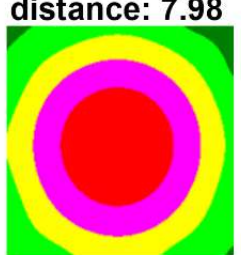

(k)

time: $\mathbf{5 . 1 4}$

distance: 12.33

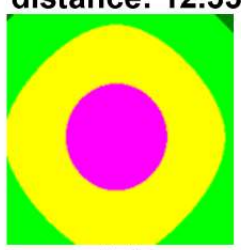

(q)
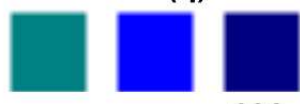

692 time: 1.81

distance: 4.35

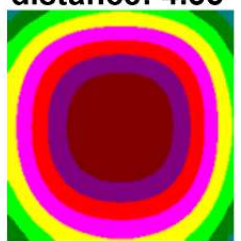

(f)

time: $\mathbf{3 . 6 3}$

distance: $\mathbf{8 . 7 0}$

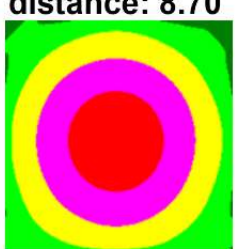

(I)

distance: 13.06

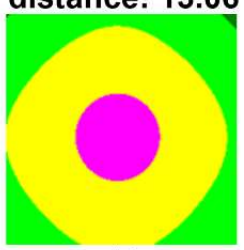

(r)

Figure 14. (a-r) Temperature profiles for steel frontal views; time(min) and distance (m).

Table 7. Dimensions of the SCS in the curve zone (for slabs).

\begin{tabular}{cccccccccc}
\hline Zone & $\boldsymbol{\theta}$ & $\boldsymbol{\Sigma} \boldsymbol{R}$ & $\boldsymbol{R} \boldsymbol{( \mathrm { m } )}$ & $\boldsymbol{\Omega}$ & $\begin{array}{c}\text { Sprays on casting } \\
\text { direction }\end{array}$ & $\begin{array}{c}\boldsymbol{d} \boldsymbol{s}_{Z N}^{\prime} \\
(\mathbf{m m})\end{array}$ & $\begin{array}{c}\boldsymbol{d} w_{Z N}^{\prime} \\
(\mathbf{m m})\end{array}$ & $\begin{array}{c}\boldsymbol{d n} w_{Z N}^{\prime} \\
(\mathbf{m m})\end{array}$ \\
\hline Curved Zone & & & & & & & & & \\
\hline $\mathbf{1}$ & 12 & 18 & 3.29 & 60 & 11 & 500 & 329 & 171 \\
\hline $\mathbf{2}$ & 8 & 26 & 4.76 & 55 & 5 & 500 & 467 & 33 \\
\hline $\mathbf{3}$ & 8 & 34 & 6.23 & 50 & 5 & 500 & 467 & 33 \\
\hline
\end{tabular}




\begin{tabular}{|c|c|c|c|c|c|c|c|c|}
\hline 4 & 11 & 45 & 8.24 & 50 & 5 & 750 & 660.5 & 89.5 \\
\hline 5 & 11 & 56 & 10.26 & 50 & 5 & 750 & 660.5 & 89.5 \\
\hline 6 & 11 & 67 & 12.28 & 50 & 5 & 750 & 660.5 & 89.5 \\
\hline 7 & 11 & 78 & 14.29 & 50 & 5 & 750 & 660.5 & 89.5 \\
\hline 8 & 10 & 88 & 16.30 & 50 & 5 & 750 & 660.5 & 89.5 \\
\hline \multicolumn{9}{|c|}{ Straight Zone } \\
\hline Zone & $\begin{array}{l}R d \\
(\mathrm{~m})\end{array}$ & $\boldsymbol{\Omega}$ & sprays & $\begin{array}{l}d s_{Z N}^{\prime} \\
\mathrm{mm})\end{array}$ & $\begin{array}{l}d w_{Z N}^{\prime} \\
(\mathrm{mm})\end{array}$ & $\begin{array}{c}d n w_{Z N}^{\prime} \\
(\mathrm{mm})\end{array}$ & & \\
\hline 9 & 18.61 & 55 & 5 & 750 & 630.4 & 119.6 & & \\
\hline 10 & 20.92 & 55 & 5 & 750 & 630.4 & 119.6 & & \\
\hline 11 & 23.22 & 55 & 5 & 750 & 630.4 & 119.6 & & \\
\hline 12 & 25.52 & 55 & 5 & 750 & 630.4 & 119.6 & & \\
\hline
\end{tabular}

Table 8. Operating conditions of the SCS in the curve zone (for slabs).

\begin{tabular}{ccccc}
\hline Zone & $\begin{array}{c}\text { Sprays on the lateral } \\
\text { direction }\end{array}$ & $\begin{array}{c}\text { Nozzle diameter } \\
(\mathbf{m m})\end{array}$ & $\mathbf{\Omega}$ & $\begin{array}{c}\boldsymbol{D}_{\boldsymbol{b s}} \\
(\mathbf{m m})\end{array}$ \\
\hline $\mathbf{1}$ & 5 & 2.5 & 40 & 180 \\
\hline $\mathbf{3}$ & 5 & 2.5 & 40 & 180 \\
\hline $\mathbf{4}$ & 4 & 2.5 & 45 & 150 \\
\hline $\mathbf{5}$ & 4 & 2.5 & 45 & 150 \\
\hline $\mathbf{6}$ & 3 & 3 & 30 & 120 \\
\hline $\mathbf{7}$ & 3 & 3 & 30 & 120 \\
\hline $\mathbf{8}$ & 3 & 3 & 30 & 120 \\
\hline $\mathbf{9}$ & 3 & 3 & 30 & 120 \\
\hline $\mathbf{1 0}$ & 3 & 3 & 30 & 120 \\
\hline $\mathbf{1 1}$ & 3 & 3 & 30 & 120 \\
\hline $\mathbf{1 2}$ & 3 & 3 & 30 & 120 \\
\hline & 3 & 30 & 120 \\
\hline
\end{tabular}

Figure 16 shows the slab left cross-sections, from the meniscus level to the end, the temperature profiles, which are the same as the right cross-sections due to symmetry reasons. It is possible to observe that the general heat removal rate increases when the slab casting speed is slow due to longer residence times under cooling effects in the SCS. Moreover, it is more complicated to appreciate the influence of different heat removal conditions due to the intensity of the heat flux conducted from the big slab core.

Figures 17a and 17b show the effects of the casting speed on the surface temperature for the narrow and broad faces of the slab. Here it is notorious the difference between surface temperature for both simulations. The slab casting speed at $1.0 \mathrm{~m} / \mathrm{min}$. runs slowly, and the heat removal is much more intense than the slab cast at $1.30 \mathrm{~m} / \mathrm{min}$.; furthermore, the surface temperatures for narrow and wide slab surfaces are also higher, as seen 
in Figure $17 \mathrm{~b}$, but the difference between the minimum and maximum temperature on the SCS is smaller due to the heat conducted from the slab core. Tables $\mathbf{9}$ and $\mathbf{1 0}$ show the differences between the actual temperatures measured using a digital pyrometer directly and the temperatures simulated computationally, showing the lowest and highest temperatures. These correspond inversely to the highest and lowest water flow rates applied.

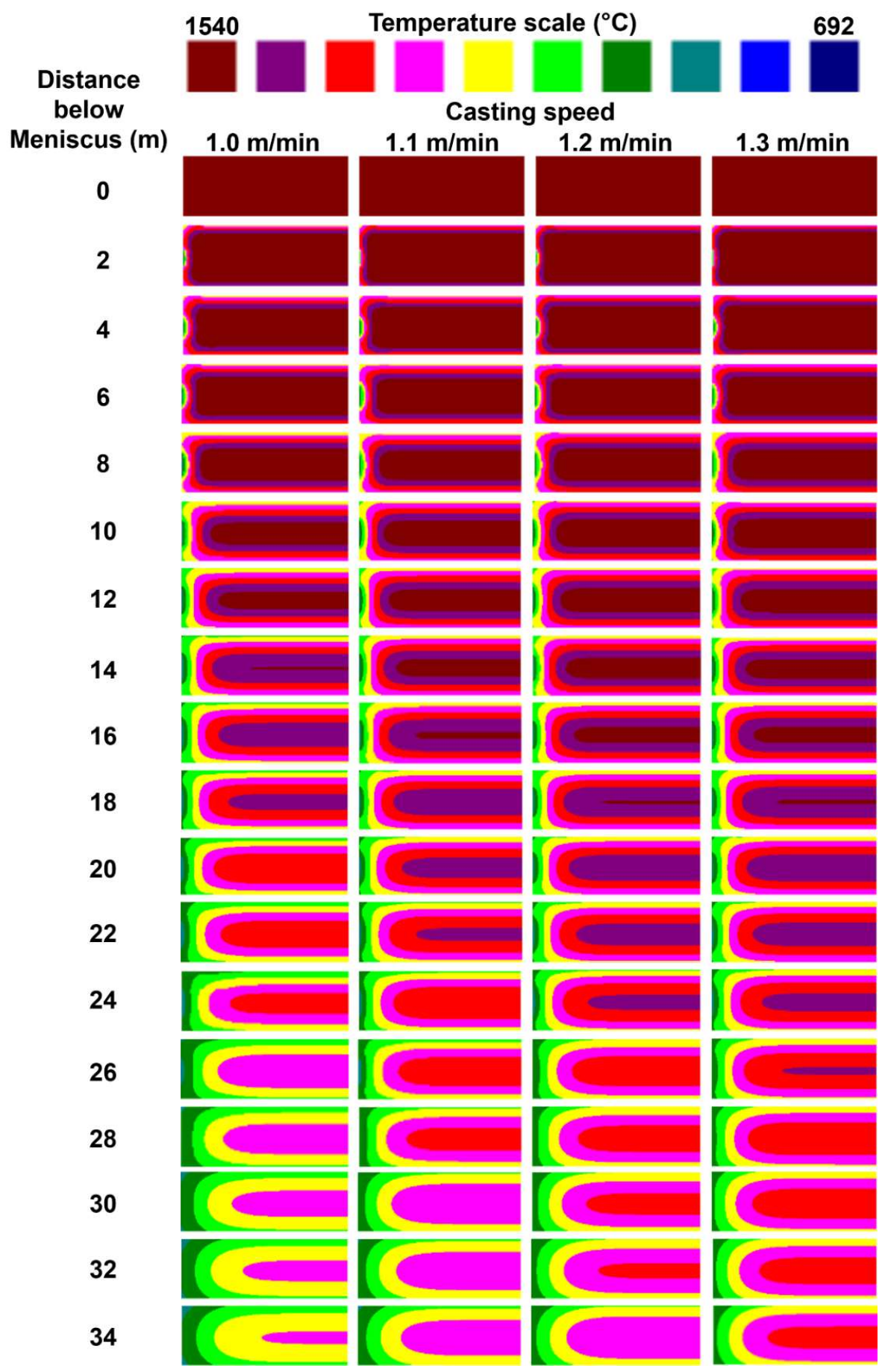

Figure 16. Temperature profiles calculated computationally for case (3) considering a slab cast running at 4 differents cast speeds (perpendicular views to the cast direction for the slabs). 


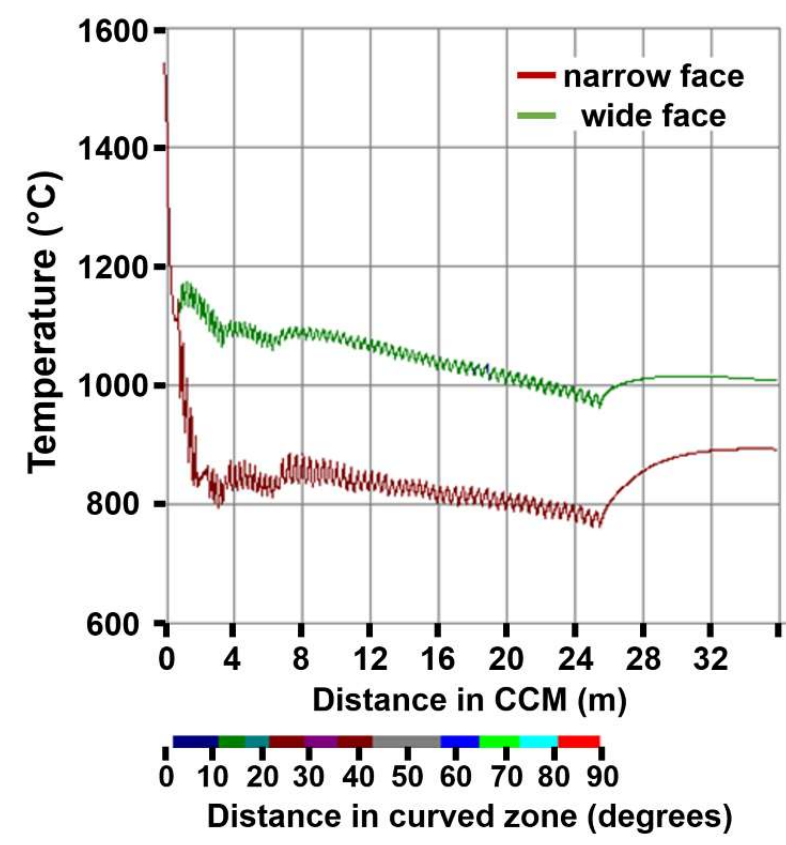

(a)
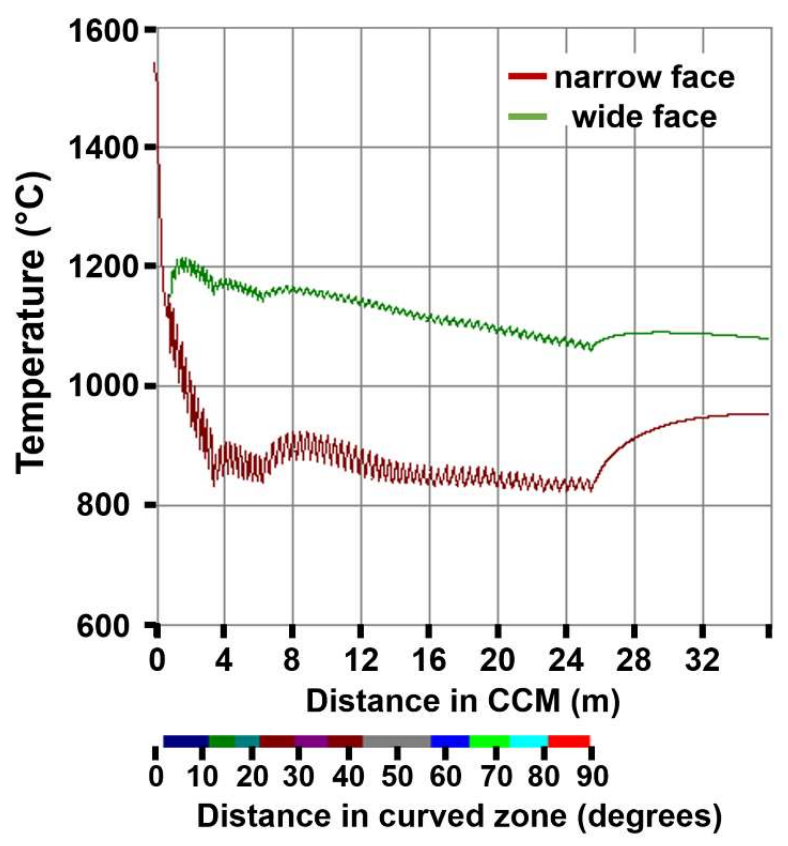

(b)

Figure 17. Surface temperatures on narrow and wide slab faces, (a) for a casting speed = $1.0 \mathrm{~m} / \mathrm{min}$, and (b) for a casting speed $=1.30 \mathrm{~m} / \mathrm{min}$.

Table 9. Calculated errors for the simulated billets case (1)

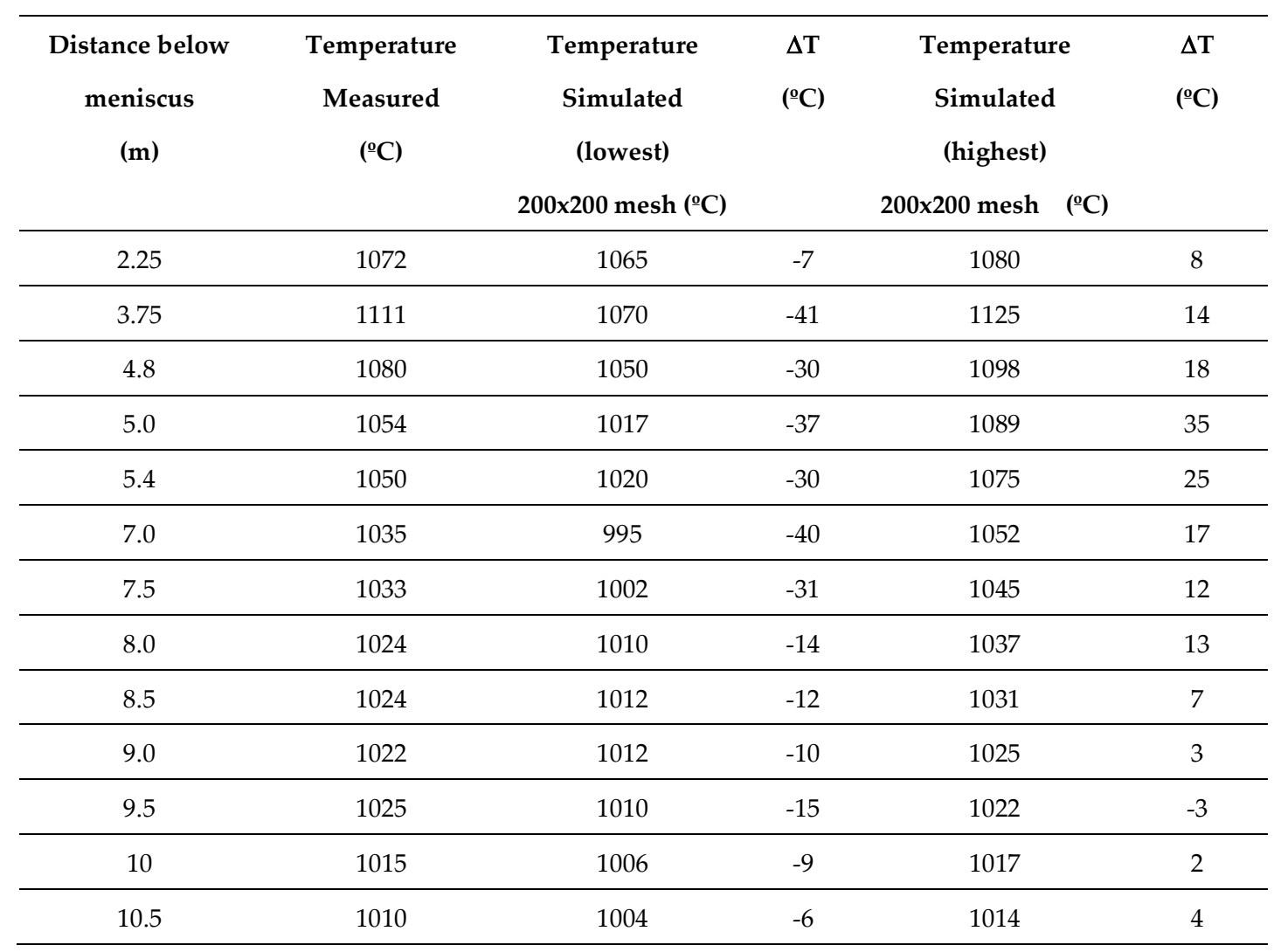


Table 10. Calculated errors for the simulated billets case (2).

\begin{tabular}{|c|c|c|c|c|c|}
\hline $\begin{array}{l}\text { Distance below } \\
\text { meniscus } \\
\text { (m) }\end{array}$ & $\begin{array}{c}\text { Temperature } \\
\text { Measured } \\
\left.\text { ( }{ }^{\circ} \mathrm{C}\right)\end{array}$ & $\begin{array}{c}\text { Temperature } \\
\text { Simulated } \\
\text { (lowest) } \\
200 \times 200 \text { mesh }\left({ }^{\circ} \mathrm{C}\right)\end{array}$ & $\begin{array}{l}\Delta \mathrm{T} \\
\left({ }^{\circ} \mathrm{C}\right)\end{array}$ & $\begin{array}{c}\text { Temperature } \\
\text { Simulated } \\
\text { (highest) } \\
200 \times 200 \text { mesh }\left({ }^{\circ} \mathrm{C}\right)\end{array}$ & $\begin{array}{c}\Delta \mathrm{T} \\
\left({ }^{\mathrm{o}} \mathrm{C}\right)\end{array}$ \\
\hline 1 & 975 & 920 & -55 & 1040 & 65 \\
\hline 2.5 & 1095 & 1040 & -55 & 1140 & 45 \\
\hline 3.0 & 1095 & 1030 & -65 & 1135 & 40 \\
\hline 4.1 & 1090 & 1025 & -65 & 1120 & 30 \\
\hline 4.9 & 1056 & 1001 & -55 & 1108 & 52 \\
\hline 5.5 & 1045 & 980 & -65 & 1099 & 54 \\
\hline 6.0 & 1035 & 976 & -59 & 1084 & 49 \\
\hline 6.5 & 1031 & 970 & -61 & 1068 & 37 \\
\hline 7.0 & 1035 & 980 & -55 & 1095 & 60 \\
\hline 7.5 & 1030 & 962 & -68 & 1072 & 42 \\
\hline 8.0 & 1048 & 995 & -53 & 1051 & 3 \\
\hline 8.5 & 1025 & 1001 & -24 & 1047 & 22 \\
\hline 9.0 & 1025 & 1003 & -22 & 1041 & 16 \\
\hline 9.5 & 1020 & 1002 & -18 & 1034 & 14 \\
\hline 10 & 1021 & 999 & -22 & 1028 & 7 \\
\hline
\end{tabular}

Table 11. Calculated errors for the simulated slabs case (3).

\begin{tabular}{cccc}
\hline \multicolumn{2}{c}{$\begin{array}{c}\text { Distance below } \\
\text { meniscus }(\mathrm{m})\end{array}$} & Temperature Measured & \multicolumn{2}{c}{ Temperature Simulated } & $\begin{array}{c}\Delta \mathrm{T} \\
\left({ }^{\circ} \mathrm{C}\right)\end{array}$ & $550 \times 100$ mesh & $\left({ }^{\circ} \mathrm{C}\right)$ & 10 \\
\hline 24 & 800 & 810 & 12 \\
\hline 26 & 795 & 807 & -8 \\
\hline 28 & 850 & 842 & -9 \\
\hline 30 & 860 & 851 & -8 \\
\hline 32 & 882 & 874 & -7 \\
\hline 34 & 890 & 883 & -5 \\
\hline 36 & 886 & 881 &
\end{tabular}


None of the measured temperatures is out of the range of those calculated numerically calculated. Thus, it is possible to affirm that the algorithms give a promising approach for the steel thermal behavior. The temperature differences are prominent for the second case due to the CCM geometry, and the operating conditions were notoriously different, generating significant amplitude between the minimum and maximum heat removal applied.

The temperatures in Table 11 correspond to the analysis of case 3 for a slab with a cast speed of $1.0 \mathrm{~m} / \mathrm{min}$. Due to the complexity of the CCM, it is possible to take some measures for the straight zone. The temperatures are corresponding to the internal slab face. These are remarkably similar in comparison with those calculated computationally; thus, it is possible to confirm as trustworthy the values obtained computationally.

\section{Conclusions}

A numerical algorithm designed to predict the thermal fields of continuous casting machines for billet and slabs is presented in this work and the conclusions derived from the simulations results are as follows:

1. The direct approach of calculating the heat transfer coefficients through the appropriate dimensionless numbers instead of other reported empirical correlations are suitable to predict the temperature fields in slab and billet machines.

2. The surface temperatures along the casting length of slabs and billets using this algorithm match acceptably well the temperature measurements.

3. The matching between measured temperatures and those simulated indicate that the mesh size of 200X200 nodes is large enough to get reliable thermal predictions.

4. The algorithm is versatile as it permits friendly the changes of different casting machines, including the use of different types of water spray nozzles.

Author Contributions: Conceptualization: A.R.-L., Methodology: A.R.-L., R.D.M. and A.N.-B., Software: J.R.-Á., C.R.M.-V., Formal analysis; A.R.-L., R.D.M and A.N.-B., Investigation; A.R.-L. and O.D.-M, Supervision: A.R.-L. and R.D.M. All authors have read and agreed to the published version of the manuscript.

Funding: This research was funded by Consejo Nacional de Ciencia y Tecnología (CoNaCyT), SNI, Instituto Politécnico Nacional (IPN) and Universidad Autónoma de Coahuila (UAC).

Acknowledgments: The authors wish to thank their institutions: Autonomous and Technological Institute of Mexico (ITAM), Consejo Nacional de Ciencia y Tecnología (CoNaCyT), and Instituto Politécnico Nacional (IPN) for technical and financial supports.

Conflicts of Interest: The authors declare no conflict of interest.

\section{References}

1. Blase, T.A; Guo,Z.X.; Shi, Z; Long, K; Hopkins, W.G. A 3D conjugated heat transfer model for continuous wire casting. Mat. Sci. Eng. A 2004, 365, 318-324.

2. Brimacombe, J.K. Design of continuous casting machine based on a heat-flow analysis: state-of-the-art review. Can. Metall. Quart. 1976, 15, 163-175.

3. Choudhary, S.K.; Mazumdar, D.; Ghosg, A. Mathematical modeling of heat transfer phenomena in continuous casting of steel. ISIJ Int. 1993, 33, 764-774.

4. Choudhary, S.K.; Mazumdar, D. Mathematical modeling of transport phenomena in continuous casting of steel. ISIJ Int. 1994, 34, 548-592.

5. Choudhary, S.K.; Mazumdar, D. Mathematical modeling of fluid flow, heat transfer and solidification phenomena in continuous casting of steel. Steel Res. Int. 1995, 66, 199-205.

6. Crank, J.; Nicholson, P. A practical method for numerical evaluation of partial differential equations of the heat conduction type. Proc. Cam. Phil. Soc. 1947, 43, 50-67. 
7. Das, S.K. Evaluation of solid-liquid interface profile during continuous casting by a spline-based formalism. Bull. Mater. Sci. 2001, 24, 373-378.

8. Fachinotti, V.D.; Cardona, A. Constitutive models for steel under continuous casting conditions. J. Mater. Process Technol. 2003, 135, 30-43.

9. Gerald, C.F.; Wheatley, P.O. Applied Numerical Analysis; Addison Wesley Publishing: USA, 1994; pp. 6116-658.

10. Hibbins, S.G. Characterization of Heat Transfer in the Secondary Cooling System of a Continuous Slab Caster. MASc Thesis, Materials Engineering, University of British Columbia, Vancouver, Canada, 1982.

11. Janik, M.; Dyja, H. Modeling of three-dimensional temperature field inside the mold during continuous casting of steel. J. Mater. Process Technol. 2004, 157-158, 177-182.

12. Kulkarni, M.S.; Subash Babu, A. Manging quality in continuous casting process using product quality model and simulated anneling. J. Mater. Process Technol. 2005, 166, 294-306.

13. Lait, J.; Brimacombe, J.K.; Weinberg, F. Mathamatical modelling of heat flow in the continuous casting of steel. Ironmak. Steelmak. 1974, 2; 90-98.

14. Li, B.Q. Numerical simulation of flow and temperature evolution during the initial phase of steady-state solidification. J. Mater. Process Technol. 1997, 71, 402-413.

15. Louhenkilpi, S.; Laitinen, E.; Nienminen, R. Real-time simulation of heat transfer in continuous casting. Met. Mater. Trans. B 1993, 24, 685-693.

16. Louhenkilpi, S. Simulation and control of heat transfer in continuous casting of Steel. Acta Polytechnica Scandinavica, Chemical Tech. Series No. 230. The Finish Academy of Technology, Finland, 1995.

17. Oliveira, M.J.; Malheiros, L.F.; Silva Ribeiro, C.A. Evaluation of the heat of solidification of cast irons from continuous cooling curves. J. Mater. Process Technol. 1999, 92-93, 25-30.

18. British Iron and Steel Research Association. Physical Constant of Some Commercial Steels at Elevated Temperatures; Butteworths Scientific Publations: London, 1978; pp. 1-38.

19. Ruhul Amin, M.; Mahajan, A. Modeling of turbulent heat transfer during the solidification process of continuous castings. J. Mater. Process Technol. 2006, 174, 155-166.

20. Savage, J.; Pritchard, W.H. The problem of rupture of the billet in the continuous casting of steel. J. Iron Steel Inst. 1954, 178, 269-277.

21. Zhang, L.; Rong, Y.M.; Shen, H.F.; Huang, T.Y. Solidification modeling in continuous casting by finite point method. J. Mater. Process Technol. 2007, 192-193, 511-517.

22. Thomas, B.G.; Samarasekera, I.V.; Brimacombe, J.K. Comparison of numerical modeling techniques for complex, twodimensional, transient heat-conduction problems. Met. Mater. Trans. B 1984, 15, 307-318.

23. Ramírez-López, A.; Aguilar-López, R.; Palomar-Pardavé, M.; Romero-Romo, M.A.; Muñóz-Negrón, D. Simulation of heat transfer in steel billets during continuous casting. Int. J. Min. Metall. Mater. 2010, 17, 403-416.

24. Ramírez-López, A.; Aguilar-López, A.; Kunold-Bello, A.; González-Trejo, J.; Palomar-Pardavé, M. Simulation factors of steel continuous casting. Int. J. Min. Metall. Mater. 2010, 17, 267-275.

25. Dauby, P.H.; Assar, M.B.; Lawson, G.D. PIV and MFC measurements in a continuous caster mould. New tools to penetrate the caster black box. La Revue de Metallurgie-CIT 2001, 98, 353-366.

26. Thomas, B.G. Chapter 14. Fluid Flow in the Mold. In Making, Shaping and Treating of Steel: Continuous Casting; Cramb, A., Ed.; AISE Steel Foundation: Pittsburgh, PA, USA, 2003, pp. 14.1-14.41

27. Thomas, B.G. Modeling of Continuous Casting Defects Related to Mold Fluid Flow. Iron Steel Tech, 2006, 3, 128-143.

28. Emling, W.H.; Waugaman, T.A.; Feldbauer, S.L.; Cramb, A.W. Subsurface mold slag entrainment in ultra-low carbon steels. In Steelmaking Conference Proc., Warrendale, PA, USA, 1994; pp. 371-379.

29. Zhao, B.; Thomas, B.G.; Vanka, S.P.; O'Malley, R.J. Transint fluid flow and superheat transport in continuous casting of steel slabs. Met. Mater. Trans. B 2005, 36, 801-823.

30. Yuan, Q.; Zhao, B.; Vanka, S.P.; Thomas, B.G. Study of computational issues in simulation of transient flow in continuous casting. Steel Res. Int. 2005, 76, 33-43.

31. Thomas, B.G.; O'Malley, R.; Shi, T.; Meng, Y.; Creech, D.; Stone, D. Validation of fluid flow and solidification simulation of a continuous thin slab caster. In Proceedings of the Ninth International Conference on Modeling of Casting, Welding and Advanced Solidification Processes, Aachen, Germany, 20-25 August 2000); pp. 769-776.

32. Su, W.; Wang, W.; Luo, S.; Jiang, D.; Zhu, M. Heat transfer and central segregation of continuous cast high carbon steel billets. J. Iron Steel Res. Int. 2014, 21,565-574.

33. Yu, Y.; Luo, X. Identification of heat transfer coefficients of steel billet in continuous casting by weight least square and improved difference evolution method. App. Therm. Engineer. 2017, 114, 36-43.

34. Zhang, J.; Chen, D.F.; Zhang, C.Q.; Wang, S.G.; Hwang, W.S. Dynamic spray cooling control model based on the tracking of velocity and superheat for the continuous casting steel. J. Mater. Process. Tech. 2016, 229, 651-658. 
35. Ramírez-López, A.; Muñoz-Negrón, D.; Palomar-Pardavé, M.; Romero-Romo, A.; Cruz-Morales, V. Using finitedifference to solve heat removal in metallic sections industrially produced. AIP Conference Proceedings 1479 (1), 2012.

36. Zhang, J.; Chen, D.F.; Zhang, C.Q.; Wang, S.G.; Hwang, W.S.; Han, M.R. Effects of an even secondary cooling mode on the temperature and stress fields of round billet continuous casting steel. J. Mater. Process. Tech. 2015, 222, 315-326.

37. Wang, Z.; Yao, M.; Wang, X.; Zhang, X.; Yang, L.; Lu, H.; Wang, X. Inverse problem-coupled heat transfer model for steel continuous casting. J. Mater. Process. Tech. 2014, 214, 44-49.

38. Lally, B.; Biegler, L.; Henein, H. Finite difference heat-transfer modeling for continuous casting. Met. Mater. Trans. B 1990, 21, 761-770.

39. Chen, Y.; Peng, Z.; Wu, L.; Zhao, L.; Wang, M.; Bao, Y. High-precision numerical simulation for the effect of casting speed on solidification of 40Cr during continuous billet casting. La Metallurgia Italiana 2015, 1, 47-51.

40. O'Connor, T.G.; Dantzing, J.A. Modeling the thin-slab continuous-casting mold. Met. Mater. Trans. B 1994, $25,443-457$.

41. Ramírez-López, A.; Muñoz-Negrón, D.; Romero-Hernández, S.; Cruz-Morales, V.; Escalera-Pérez, R. Thermal behavior of cast steel industrially produced. Adv. Mater. Res. 2012, 628, 179-182.

42. Ramírez, A.; Mosqueda, A.; Sauce, V.; Morales, R.; Ramos, A.; Solorio, G. Desarrollo de simuladores para procesos industriales. Parte II (colada continua). Revista de Metalurgia 2006, 42, 209-215. 